\title{
Amphibians and Reptiles of the Tirimbina Biological Reserve: a baseline for conservation, research and environmental education in a lowland tropical wet forest in Costa Rica
}

\author{
Branko Hilje ${ }^{1}$, Gerardo Chaves², Jeremy Klank ${ }^{2}$, Ferdy Timmerman ${ }^{3}$, Joshua Feltham ${ }^{4}$, \\ Scott Gillingwater ${ }^{5}$, Teresa Piraino ${ }^{6}$, Emmanuel Rojas-Valerio $^{7}$
}

1 Council on International Educational Exchange, 60109, Monteverde, Puntarenas, Costa Rica. 2 Escuela de Biología de la Universidad de Costa Rica, Ciudad Universitaria Rodrigo Facio, San Pedro de Montes de Oca, San José, Costa Rica. 3 Bureau Viridis-Ecological Research \& Consultancy, Randweg 30, 4104AC, Culemborg, The Netherlands. 4 Sir Sandford Fleming College, School of Environmental and Natural Resource Sciences, Frost Campus, Lindsay, Ontario, Canada. 5 Upper Thames River Conservation Authority, 1424 Clarke Road, London, Ontario, Canada. 6 WSP Canada Ltd., 582 Lancaster Street West, Kitchener, Ontario, Canada 7 Reserva Biológica Tirimbina, 41002, La Virgen de Sarapiquí, Heredia, Costa Rica.

Corresponding author: Branko Hilje, bhilje@gmail.com

\begin{abstract}
The Tirimbina Biological Reserve is located in the lowlands on the Atlantic versant of Costa Rica. We provide an updated comprehensive herpetofauna species list and summarize the results of all the herpetofauna research conducted at Tirimbina over the last 10 years (2009-2019) across a variety of microhabitats. We also added historical records from occasional sightings and reports from researchers, staff, visitors, interns, fellows, and volunteers since the 1990s. We found 52 amphibian and 78 reptile species on the reserve, including a few species considered at-risk according to the IUCN Red List. We conclude that Tirimbina is a herpetofauna biodiversity hot spot in Costa Rica because it provides unique habitat characteristics for a variety of species, including habitat for both forest and forest-edge specialists.
\end{abstract}

\section{Keywords}

Biodiversity, frogs, herpetofauna, hot spot, lizards, primary forest, Sarapiquí

Citation: Hilje B, Chaves G, Klank J, Timmerman F, Feltham J, Gillingwater S, Piraino T, Rojas-Valerio E (2020) Amphibians and Reptiles of the Tirimbina Biological Reserve: a baseline for conservation, research and environmental education in a lowland tropical wet forest in Costa Rica. Check List 16 (6): 1633-1655. https://doi.org/10.15560/16.6.1633

\section{Introduction}

The Tirimbina Biological Reserve (TBR) preserves 345 ha of lowland tropical wet forest, one of the most diverse ecosystems in the tropics (Gentry 1992; Reserva Tirimbina 2020). TBR became a Biological Reserve in the late 1990s and was founded on a three-pillared conservation model based on ecotourism, environmental education for local elementary schools, and research by the Academic Department of TBR (Reserva Tirimbina 2020). Several research projects have been completed since then, by TBR staff and Costa Rican and international researchers, who worked independently or in collaboration with TBR. These projects have generated approximately 160 
scientific publications regarding the biodiversity and ecology of this lowland tropical wet forest. Despite several decades of research, including herpetological studies, TBR lacks a formal species list summarizing the herpetofauna inventories and research projects conducted in the reserve. This study aims to provide an updated species list for amphibians and reptiles of TBR. This list is based on formal species inventories, research studies, and incidental sightings from researchers, staff, visitors, interns, fellows and volunteers.

\section{Methods}

Study site. TBR is located in Sarapiquí county, province of Heredia, Costa Rica $\left(010^{\circ} 25^{\prime} 02^{\prime \prime} \mathrm{N}, 084^{\circ} 07^{\prime} 32^{\prime \prime} \mathrm{W}\right)$ (Fig. 1). TBR covers 345 ha of Atlantic lowland tropical wet forest at $180-220 \mathrm{~m}$ elevation; mean annual temperature is $25.3{ }^{\circ} \mathrm{C}$ (range $20.2-30.0^{\circ} \mathrm{C}$ ) and mean annual rainfall $3777 \mathrm{~mm}$ (Savage 2002; Reserva Tirimbina 2020). TBR is approximately $90 \%$ primary forest with small areas that were selectively logged in the late 1980s. The remainder of the land is comprised of secondary forest, abandoned cacao plantations, and secondary forest in early regeneration (Timmerman and Smid pers. comm.; Reserva Tirimbina 2020).

Data collection. We collected information on amphibian and reptile species in TBR from occasional sightings and reports from researchers, staff, visitors, interns, fellows and volunteers since the 1990s. In addition, we carried out herpetofauna surveys and research within TBR as described below. Survey methods included standard visual encounter surveys (VES) (Crump and Scott 1994) complimented with manipulation of species for no longer than five minutes for identification and photographs when needed. Photographs were archived at TBR and are made available to interested researchers. The sex of specimens was determined by sexual dimorphism such as tail length and width, colour patterns, tubercules, spines and dewlaps. We based our visual species identification on the characters presented by: Savage (2002), Solórzano (2004), Leenders (2016), and Leenders (2019). Frog call identification followed Cossel and Kubicki (2017).

GC and JK conducted eight surveys between October 2018 and February 2019 to determine the most abundant species present within TBR. Survey methods included standard visual encounter surveys (VES) complimented with manipulation for identification and photographs when needed (Crump and Scott 1994), acoustic surveys (Rand and Drewry 1994) and breeding site surveys (Scott and Woodward 1994). Surveys were carried out on the Corteza, Hunter, Cacaotal, Isla, Ceiba, Botarrama and Tirimbina trails (Fig. 1). These trails cover most of the different habitats found in TBR, including primary and secondary forests, Tirimbina River shoreline, forest streams, ponds, swamps and open grassy areas. Collected specimens were euthanized with lidocaine, fixed with $10 \%$ buffered formaldehyde, and stored in $70 \%$ ethanol; specimens were deposited in the herpetofauna collection at the Museo de Zoología de la Universidad de Costa Rica (MZUCR). All research and collection were carried out under approved permits by the National Conservation Areas System from the Environment and Energy Agency, Costa Rica, R-SINAC-PNISE-002-2018 and R-SINAC-PNI-ACAHN-27-2019.

FT and a field assistant conducted snake surveys in TBR from February to July 2009 (Timmerman and Smid pers. comm.). Trail VES (Crump and Scott 1994) were carried out according to a rotational scheme with each accessible trail surveyed every six weeks during the day, dusk, and at night. Furthermore, the full length and banks of all streams within TBR were surveyed once during day and night for the study period. During surveys for snakes, the trails, the forest floor and vegetation adjacent to the trails to a lateral distance of approximately $3 \mathrm{~m}$, and arboreal habitat up to a height of $3 \mathrm{~m}$ were included. A pace of approximately $1.5 \mathrm{~km} / \mathrm{h}$ was maintained during surveys. Stream surveys were conducted according to the same method, but at a slower pace since there were no maintained trails at the streams to allow unimpeded access. Additionally, other areas of TBR were sampled haphazardly including sections along the Tirimbina and Sarapiquí rivers; portions along the TBR borders; a large part of the island within the Sarapiquí River; off-trail sections between mapped trails and streams; the garden area; along the road that passes the reserve; and on the forest trails themselves between scheduled surveys. Efforts to find arboreal species were made by searching in and under recently fallen bromeliads and other fallen debris, while efforts to find elusive terrestrial and fossorial species were made by searching beneath logs, rocks, leaf-litter and palm fronds. Such objects were carefully flipped, often using snake hooks, and replaced as they were found. Study results include preserved specimens as well as photographic records by guides, students, tourists, and other visitors.

In April $2010 \mathrm{JF}$ and eight students conducted VES on $750 \mathrm{~m}$ transects of the Viejo, Hunter and Ajillo trails. The Viejo transect started and ended at the Tirimbina River but rose steeply in elevation, leveled off and then descended steeply back to the river. The Hunter transect descended to and then followed a second or third-order stream while the Ajillo transect followed the top of a ridge adjacent to the Tirimbina River. Each 750 m transect was divided into $15 \mathrm{~m}$ sampling segments of which 20 were sampled each time the transect was surveyed. The segments for sampling were determined by generating 20 numbers between one and 50 using the "randbetween" function in Excel. Surveys were conducted between 0800-1200 and 2000-0000h. The Viejo and Hunter transects were surveyed three times in the morning and three times at night and the Ajillo trail was surveyed twice in the morning and twice at night. Survey teams consisted of four surveyors. Each team surveyed each transect once at night and once during the day. VES were conducted without any active searching such 

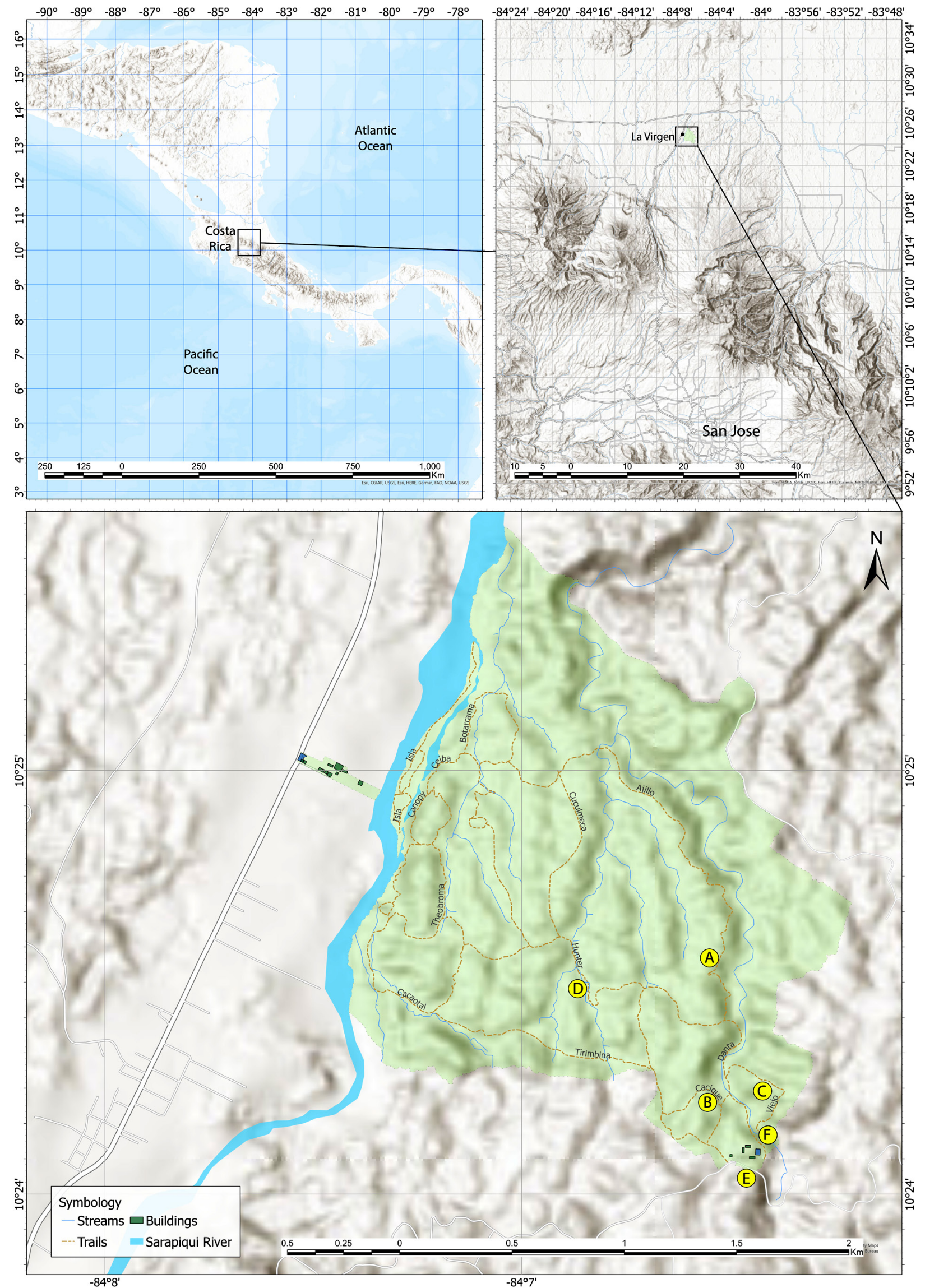

Figure 1. Map of TBR showing the main trails and water bodies (see Table 1 for habitat types). 
Table 1. Species of amphibians and reptiles of TBR and their IUCN Red List category status (current to November 2020) (IUCN 2020). Habitat types are identified as follows: primary forests (PF), secondary forests (SF), cacao plantation (CP), open grassy areas (OG), garden $(\mathrm{G})$, riparian forests (RF), stream forests (StrF), ponds (P) and swamps (S).

\begin{tabular}{|c|c|c|c|c|c|c|c|c|c|c|}
\hline \multirow{2}{*}{ Taxon } & \multirow{2}{*}{ IUCN Status } & \multicolumn{8}{|c|}{ Habitat Types } & \multirow{2}{*}{ Voucher } \\
\hline & & PF & SF & CP & OG & G & $\mathrm{RF}$ & $\mathbf{P}$ & $\mathrm{s}$ & \\
\hline \multicolumn{11}{|l|}{ CLASS AMPHIBIA } \\
\hline \multirow{2}{*}{\multicolumn{11}{|c|}{$\begin{array}{l}\text { Order Gymnophiona } \\
\text { Dermophiidae }\end{array}$}} \\
\hline & & & & & & & & & & \\
\hline Gymnopis multiplicata (Peters, 1874) & LC & & $x$ & & & $x$ & & & & UCR23063 \\
\hline \multicolumn{11}{|l|}{ Order Caudata } \\
\hline \multicolumn{11}{|l|}{ Plethodontidae } \\
\hline Bolitoglossa alvaradoi (Taylor, 1954) & EN & & & & & & & & & Photo only \\
\hline Bolitoglossa colonnea (Dunn, 1924) & $\mathrm{LC}$ & & & & & & & & & Photo only \\
\hline Bolitoglossa striatula (Noble, 1918) & $\mathrm{LC}$ & & & & & & & & & Photo only \\
\hline Oedipina gracilis (Taylor, 1952) & EN & & & & & & & & & Photo only \\
\hline \multicolumn{11}{|l|}{ Order Anura } \\
\hline Bufonidae & & & & & & & & & & \\
\hline Incilius melanochlorus (Cope, 1877) & $\mathrm{LC}$ & $x$ & $x$ & $x$ & & & $x$ & & & UCR23088 \\
\hline Incilius valliceps (Wiegmann, 1833) & $\mathrm{LC}$ & & & & $x$ & & & $x$ & & UCR23197 \\
\hline Rhaebo haematiticus (Cope, 1862) & $\mathrm{LC}$ & $x$ & $x$ & $x$ & $x$ & & $x$ & & & UCR23065 \\
\hline Rhinella horribilis (Wiegmann, 1833) & $\mathrm{LC}$ & $x$ & $x$ & $x$ & $x$ & $x$ & $\mathrm{x}$ & $x$ & & UCR23090 \\
\hline Centrolenidae & & & & & & & & & & \\
\hline Cochranella granulosa (Taylor, 1949) & $\mathrm{LC}$ & $x$ & & & & & $\mathrm{x}$ & & & Photo only \\
\hline Espadarana prosoblepon (Boettger, 1892) & $\mathrm{LC}$ & $x$ & $x$ & & & & $x$ & & & UCR23086 \\
\hline Hyalinobatrachium fleischmanni (Boettger, 1893) & LC & & $x$ & $x$ & & & $x$ & & & Photo only \\
\hline Hyalinobatrachium valerioi (Dunn, 1931) & $\mathrm{LC}$ & $x$ & & & & & $x$ & & & UCR23250 \\
\hline Sachatamia albomaculata (Taylor, 1949) & LC & & & & & & $x$ & & & UCR23248 \\
\hline Teratohyla pulverata (Peters, 1873) & LC & & & & & & $x$ & & & Photo only \\
\hline Teratohyla spinosa (Taylor, 1949) & $\mathrm{LC}$ & $x$ & & & & & $\mathrm{x}$ & & & UCR23084 \\
\hline Craugastoridae & & & & & & & & & & \\
\hline Craugastor bransfordii (Cope, 1885) & LC & $x$ & $x$ & $x$ & $x$ & $x$ & $x$ & & & UCR23071 \\
\hline Craugastor fitzingeri (Schmidt, 1857) & $\mathrm{LC}$ & $x$ & $x$ & $x$ & $x$ & $\mathrm{x}$ & $x$ & & $x$ & UCR23067 \\
\hline Craugastor crassidigitus (Taylor, 1952) & $\mathrm{LC}$ & $x$ & $x$ & & & & & & & Photo only \\
\hline Craugastor gollmeri (Peters, 1863) & LC & $x$ & $x$ & & & & & & & UCR23105 \\
\hline Craugastor megacephalus (Cope, 1875) & $\mathrm{LC}$ & $x$ & $x$ & & & & & & & UCR23055 \\
\hline Craugastor mimus (Taylor, 1955) & $\mathrm{LC}$ & $x$ & $x$ & & & & & & & UCR23108 \\
\hline Craugastor noblei (Barbour \& Dunn, 1921) & LC & $x$ & $x$ & & & & & & & UCR23080 \\
\hline Craugastor persimilis (Barbour, 1926) & VU & $x$ & $x$ & & & & $x$ & & & UCR23100 \\
\hline Craugastor talamancae (Dunn, 1931) & $\mathrm{LC}$ & $x$ & & & & & & & & Photo only \\
\hline Pristimantis cerasinus (Cope, 1875) & LC & $x$ & $x$ & & & & & & & UCR23111 \\
\hline Pristimantis cruentus (Peters, 1873) & LC & $x$ & $x$ & & & & & & & Photo only \\
\hline Pristimantis ridens (Cope, 1866) & LC & $x$ & $x$ & $x$ & $x$ & $x$ & $x$ & & $x$ & UCR23056 \\
\hline Dendrobatidae & & & & & & & & & & \\
\hline Dendrobates auratus (Girard, 1855) & $\mathrm{LC}$ & $x$ & $x$ & & & $x$ & & & & UCR23072 \\
\hline Oophaga pumilio (Schmidt, 1857) & $\mathrm{LC}$ & $x$ & $x$ & $x$ & & $x$ & $x$ & & & UCR23073 \\
\hline Phyllobates lugubris (Schmidt, 1857) & $\mathrm{LC}$ & $x$ & & & & & & & & Photo only \\
\hline Eleutherodactylidae & & & & & & & & & & \\
\hline Diasporus diastema (Cope, 1875) & LC & $x$ & $x$ & $x$ & & $x$ & $x$ & & $x$ & UCR23104 \\
\hline Phyllomedusidae & & & & & & & & & & \\
\hline Agalychnis callidryas (Cope, 1862) & $\mathrm{LC}$ & $x$ & $x$ & $x$ & & $x$ & & & $x$ & UCR23064 \\
\hline Agalychnis saltator (Taylor, 1955) & $\mathrm{LC}$ & & & & & & & & $x$ & Photo only \\
\hline Cruziohyla sylviae (Gray, 2018) & $\mathrm{NE}$ & & & & & & & & & Photo only \\
\hline Hylidae & & & & & & & & & & \\
\hline Dendropsophus ebraccatus (Cope, 1874) & LC & & & $x$ & & & & & $x$ & UCR23249 \\
\hline Dendropsophus phlebodes (Stejneger, 1906) & LC & & $x$ & & & & $x$ & & $x$ & UCR23188 \\
\hline Boana rufitela (Fouquette, 1961) & $\mathrm{LC}$ & $x$ & & $x$ & & & $x$ & $x$ & $x$ & UCR23053 \\
\hline Scinax boulengeri (Cope, 1887) & $\mathrm{LC}$ & $x$ & $x$ & $x$ & & & & $x$ & $x$ & UCR23373 \\
\hline Scinax elaeochroa (Cope, 1875) & $\mathrm{LC}$ & $x$ & $x$ & $x$ & & & $\mathrm{x}$ & & $x$ & UCR23069 \\
\hline Smilisca manisorum (Duméril \& Bibron, 1841) & LC & & $x$ & & & & $x$ & & & UCR23195 \\
\hline Smilisca phaeota (Cope, 1862) & LC & & $x$ & & & & & & & Photo only \\
\hline Smilisca puma (Cope, 1885) & $\mathrm{LC}$ & & $x$ & $x$ & $x$ & & & & $x$ & UCR23194 \\
\hline Smilisca sordida (Peters, 1863) & $\mathrm{LC}$ & $x$ & $x$ & $x$ & $x$ & & $x$ & & & UCR23187 \\
\hline Leptodactylidae & & & & & & & & & & \\
\hline Leptodactylus fragilis (Brocchi, 1877) & LC & & & & $x$ & & & & & Photo only \\
\hline Leptodactylus melanonotus (Hallowell, 1861) & $\mathrm{LC}$ & & $x$ & $x$ & $x$ & & $x$ & & & UCR23096 \\
\hline Leptodactylus savagei (Heyer, 2005) & LC & & $x$ & $x$ & & $x$ & & & $x$ & UCR23087 \\
\hline Leptodactylus poecilochilus (Cope, 1862) & $\mathrm{LC}$ & & $x$ & & & & & & & Photo only \\
\hline Microhylidae & & & & & & & & & & \\
\hline Hypopachus pictiventris (Cope, 1885) & $\mathrm{LC}$ & $x$ & & & & & & & & UCR23109 \\
\hline Ranidae & & & & & & & & & & \\
\hline Lithobates taylori (Smith, 1959) & $\mathrm{LC}$ & & & & & & & & $x$ & UCR23052 \\
\hline Lithobates vaillanti (Brocchi, 1877) & LC & & $x$ & $x$ & $x$ & & $\mathrm{x}$ & $x$ & $x$ & UCR23116 \\
\hline Lithobates warszewitschii (Schmidt, 1857) & $\mathrm{LC}$ & $x$ & $x$ & $x$ & & & $\mathrm{x}$ & $x$ & $\mathrm{x}$ & UCR23070 \\
\hline
\end{tabular}




\begin{tabular}{|c|c|c|c|c|c|c|c|c|c|c|}
\hline \multirow{2}{*}{ Taxon } & \multirow{2}{*}{ IUCN Status } & \multicolumn{8}{|c|}{ Habitat Types } & \multirow{2}{*}{ Voucher } \\
\hline & & PF & SF & CP & OG & G & RF & $\mathbf{P}$ & $\mathrm{s}$ & \\
\hline \multicolumn{11}{|l|}{ CLASS REPTILIA } \\
\hline \multicolumn{11}{|l|}{ Order Crocodylia } \\
\hline \multicolumn{11}{|l|}{ Alligatoridae } \\
\hline Caiman crocodilus (Linnaeus, 1758) & $\mathrm{LC}$ & $x$ & & & & & & & $x$ & Photo only \\
\hline Order Squamata & & & & & & & & & & \\
\hline Suborder Sauria & & & & & & & & & & \\
\hline Corytophanidae & & & & & & & & & & \\
\hline Corytophanes cristatus (Merrem 1820) & $\mathrm{LC}$ & & $x$ & & & & $x$ & & & UCR23252 \\
\hline Basiliscus plumifrons (Cope, 1875) & $\mathrm{LC}$ & $x$ & $x$ & $x$ & & & $x$ & & $x$ & UCR23082 \\
\hline Basiliscus vittatus (Wiegmann, 1828) & $\mathrm{LC}$ & & $x$ & & $x$ & & $x$ & & & Photo only \\
\hline Dactyloidae & & & & & & & & & & \\
\hline Anolis biporcatus (Wiegmann, 1834) & $\mathrm{LC}$ & & $x$ & & & & & & & \\
\hline Anolis capito (Peters, 1863) & $\mathrm{LC}$ & & $x$ & & & & $x$ & & & UCR23192 \\
\hline Anolis carpenteri (Echelle \& Fitch, 1971) & $\mathrm{LC}$ & $x$ & & & & & & & & Photo only \\
\hline Anolis pentaprion (Cope, 1863) & LC & $x$ & & & & & & & & Photo only \\
\hline Anolis lemurinus (Cope, 1861) & $\mathrm{LC}$ & $x$ & & & & & & & & UCR23091 \\
\hline Anolis limifrons (Cope, 1871) & LC & $x$ & $x$ & $x$ & $x$ & $x$ & $\mathrm{x}$ & & $x$ & UCR23103 \\
\hline Anolis humilis (Peters, 1863) & LC & $x$ & $x$ & $x$ & & & $x$ & & & UCR23097 \\
\hline Anolis oxylophus (Cope, 1868) & LC & $x$ & & $x$ & & & $x$ & & & UCR23098 \\
\hline Diploglossidae & & & & & & & & & & \\
\hline Diplogossus bilobatus (0'Shaughnessy, 1874) & LC & & $x$ & & & & & & & \\
\hline Gekkonidae & & & & & & & & & & \\
\hline Hemidactylus frenatus (Schlegel, 1836) & LC & & & & & $x$ & & & & UCR23200 \\
\hline Lepidodactylus lugubris (Duméril \& Bibron, 1836) & LC & & & & & $x$ & & & & UCR23093 \\
\hline Iguanidae & & & $x$ & & & & $x$ & & & \\
\hline Iguana iguana (Linnaeus, 1758) & $\mathrm{LC}$ & & & & & $x$ & $x$ & & & Photo only \\
\hline Phyllodactylidae & & & & & & & & & & \\
\hline Thecadactylus rapicauda (Houttuyn, 1782) & LC & & & $x$ & $x$ & & & & & UCR23257 \\
\hline Polychrotidae & & & & & & & & & & \\
\hline Polychrus gutturosus (Berthold, 1845) & $\mathrm{LC}$ & & & & & $x$ & & & & Photo only \\
\hline Scincidae & & & & & & & & & & \\
\hline Marisora brachypoda (Taylor, 1956) & $\mathrm{LC}$ & & & & & & & & & Photo only \\
\hline Scincella cherriei (Cope, 1893) & LC & $x$ & $x$ & & & & & & & UCR23092 \\
\hline Sphaerodactylidae & & & & & & & & & & \\
\hline Gonatodes albogularis (Duméril \& Bibron, 1836) & $\mathrm{LC}$ & & & $x$ & & $x$ & & & & UCR23074 \\
\hline Lepidoblepharis xanthostigma (Noble, 1916) & LC & & $x$ & & & & & & & UCR23054 \\
\hline Sphaerodactylus homolepis (Cope, 1886) & $\mathrm{LC}$ & $x$ & $x$ & & & & & & & UCR23261 \\
\hline Teiidae & & & & & & & & & & \\
\hline Holcosus quadrilineatus (Hallowell, 1861) & LC & & & & & $x$ & & & & \\
\hline Holcosus festivus (Lichtenstein, 1856) & LC & & $x$ & $x$ & & $\mathrm{x}$ & & & & UCR23095 \\
\hline Xantusiidae & & & & & & & & & & \\
\hline Lepidophyma flavimaculatum (Duméril, 1851) & LC & $x$ & $x$ & & & & & & & UCR23260 \\
\hline Suborder Serpentes & & & & & & & & & & \\
\hline Boidae & & & & & & & & & & \\
\hline Boa imperator (Daudin, 1803) & $\mathrm{LC}$ & & $x$ & & $x$ & & & & & UCR23058 \\
\hline Corallus annulatus (Cope, 1875) & $\mathrm{LC}$ & & $x$ & & $x$ & & & & & UCR23061 \\
\hline Colubridae & & & & & & & & & & \\
\hline Chironius grandisquamis (Peters, 1869) & LC & & $x$ & & & $x$ & & & & Photo only \\
\hline Dendrophidion percarinatum (Cope, 1893) & LC & & $x$ & & & $x$ & $\mathrm{x}$ & & & Photo only \\
\hline Dendrophidion apharocybe (Cadle, 2012 & LC & & $x$ & & & & & & & Photo only \\
\hline Dendrophidion rufferminorum (Cadle \& Savage 2012) & $\mathrm{LC}$ & & $x$ & & & & & & & \\
\hline Drymobius margaritifferus (Schlegel, 1837) & $\mathrm{LC}$ & $x$ & $x$ & & & & & & & Photo only \\
\hline Lampropeltis abnorma (Bocourt, 1886) & LC & & $x$ & & & & & & & Photo only \\
\hline Mastigodryas melanolomus (Cope, 1868) & LC & & $x$ & & & & $x$ & & & UCR23050 \\
\hline Leptophis ahaetulla (Linnaeus, 1758) & LC & & $x$ & & & & & & & Photo only \\
\hline Leptophis depressirostris (Cope, 1861) & LC & & $x$ & & & & & & & UCR23378 \\
\hline Leptophis nebulosus (Oliver, 1942) & $\mathrm{LC}$ & & $x$ & & & & $x$ & & & Photo only \\
\hline $\begin{array}{l}\text { Oxybelis koehleri (Jadin, Blair, Orlofske, Jowers, Rivas, Vitt, Ray, } \\
\text { Smith \& Murphy, 2020) }\end{array}$ & $\mathrm{LC}$ & & $x$ & & & & & & & Photo only \\
\hline Oxybelis brevirostris (Cope, 1861) & LC & & $x$ & & & & $x$ & & & Photo only \\
\hline Oxybelis fulgidus (Daudin, 1803) & LC & & $x$ & & & & & & & Photo only \\
\hline Phrynonax poecilonotus (Günther, 1858) & $\mathrm{LC}$ & & $x$ & & & & $x$ & & & Photo only \\
\hline Scaphiodontophis annulatus (Duméril, Bibron \& Duméril, 1854) & $\mathrm{LC}$ & & $x$ & & & & & & & Photo only \\
\hline Spilotes pullatus (Linnaeus, 1758) & LC & & $x$ & & & & $x$ & & & Photo only \\
\hline Stenorrhina degenhardtii (Berthold, 1846) & LC & & $x$ & & & & & & & Photo only \\
\hline Tantilla supracincta (Peters, 1863) & $\mathrm{LC}$ & & & & & & & & & Photo only \\
\hline Dipsadidae & & & & & & & & & & \\
\hline Amastridium veliferum (Cope, 1860) & $\mathrm{LC}$ & $x$ & & & & & & & & UCR23190 \\
\hline Clelia clelia (Daudin, 1803) & $\mathrm{LC}$ & & $x$ & & & & & & & Photo only \\
\hline Coniophanes fissidens (Günther, 1858) & $\mathrm{LC}$ & & $x$ & & & & & & & Photo only \\
\hline Dipsas articulata (Cope, 1868) & LC & $x$ & & & & & & & & UCR23193 \\
\hline Enuliophis sclateri (Boulenger, 1894) & LC & $x$ & & & & $x$ & & & & UCR23062 \\
\hline Erythrolamprus mimus (Cope, 1868) & LC & $x$ & & & & & & & & Photo only \\
\hline
\end{tabular}




\begin{tabular}{|c|c|c|c|c|c|c|c|c|c|c|}
\hline \multirow{2}{*}{ Taxon } & \multirow{2}{*}{ IUCN Status } & \multicolumn{8}{|c|}{ Habitat Types } & \multirow{2}{*}{ Voucher } \\
\hline & & PF & SF & CP & OG & G & RF & $\mathbf{P}$ & $S$ & \\
\hline Geophis hoffmanni (Peters, 1859) & $\mathrm{LC}$ & $x$ & & & & $x$ & & & & Photo only \\
\hline Hydromorphus concolor (Peters, 1859) & $\mathrm{LC}$ & & & & & & $x$ & & & Photo only \\
\hline Imantodes cenchoa (Linnaeus, 1758) & $\mathrm{LC}$ & & $x$ & & & $x$ & $x$ & & $x$ & UCR23076 \\
\hline Imantodes inornatus (Boulenger, 1896) & $\mathrm{LC}$ & & & & & & & & & Photo only \\
\hline Leptodeira rhombifera (Günther, 1872) & LC & & & & & & & & $x$ & Photo only \\
\hline Leptodeira septentrionalis (Kennicott, 1859) & LC & $x$ & $x$ & & & $x$ & $x$ & & $x$ & UCR23106 \\
\hline Ninia maculata (Peters, 1861) & LC & $x$ & & & & & & & & Photo only \\
\hline Ninia sebae (Duméril, Bibron \& Duméril, 1854) & $\mathrm{LC}$ & $x$ & $x$ & & & $x$ & $x$ & & & UCR23258 \\
\hline Nothopsis rugosus (Cope, 1871) & LC & & $x$ & & & & & & & Photo only \\
\hline Oxyrhopus petolarius (Linnaeus, 1758) & LC & & $x$ & & & & & & & Photo only \\
\hline Pliocercus euryzonus (Cope, 1862) & LC & & $x$ & & & & & & & Photo only \\
\hline Rhadinaea decorata (Günther, 1858) & LC & $x$ & $x$ & $x$ & & & & & & UCR23094 \\
\hline Sibon longifrenis (Stejneger, 1909) & $\mathrm{LC}$ & & & & & & & & $x$ & Photo only \\
\hline Sibon nebulatus (Linnaeus, 1758) & $\mathrm{LC}$ & & $x$ & $x$ & & & & & & UCR23051 \\
\hline Tretanorhinus nigroluteus (Cope, 1861) & $\mathrm{LC}$ & & & & & & $x$ & $x$ & & UCR23374 \\
\hline Xenodon angustirostris (Wied-Neuwied, 1824) & $\mathrm{LC}$ & $x$ & $x$ & & & & & & & UCR23059 \\
\hline \multicolumn{11}{|l|}{ Elapidae } \\
\hline Micrurus alleni (Schmidt, 1936) & LC & $x$ & $x$ & & & & $x$ & & $x$ & UCR23079 \\
\hline Micrurus multifasciatus (Jan, 1858) & LC & & & & & & & & & Photo only \\
\hline Micrurus mosquitensis (Schmidt, 1933) & $\mathrm{LC}$ & $x$ & $x$ & & & & & & & Photo only \\
\hline \multicolumn{11}{|l|}{ Viperidae } \\
\hline Bothriechis schlegelii (Berthold, 1846) & LC & & $x$ & & & & $x$ & & & Photo only \\
\hline Bothrops asper (Garman, 1884) & $\mathrm{LC}$ & $x$ & $x$ & $x$ & & $x$ & $x$ & & $x$ & UCR23081 \\
\hline Lachesis stenophrys (Cope, 1875) & Not evaluated & & & & & & & & & Photo only \\
\hline Porthidium nasutum (Bocourt, 1868) & $\mathrm{LC}$ & $x$ & $x$ & & & & & & & UCR23107 \\
\hline \multicolumn{11}{|l|}{ Order Testudines } \\
\hline \multicolumn{11}{|l|}{ Geoemydidae } \\
\hline Rhinoclemmys funerea (Cope, 1875) & NT & & $x$ & & & & $x$ & $x$ & & Photo only \\
\hline \multicolumn{11}{|l|}{ Kinosternidae } \\
\hline Kinosternon leucostomum (Duméril \& Bibron, 1851) & Not evaluated & & $x$ & & & & & $x$ & $x$ & UCR23201 \\
\hline \multicolumn{11}{|l|}{ Chelydridae } \\
\hline Chelydra acutirostris (Peters, 1862) & $\mathrm{LC}$ & & & & & & & $x$ & & Photo only \\
\hline
\end{tabular}

as removing debris to minimize the effect of surveys on habitat. Surveyors used flashlights during the day and at night to improve visibility and probability of detection of animals. All amphibians and reptiles observed within $1.5 \mathrm{~m}$ on either side of the trail and up to $3 \mathrm{~m}$ above the rainforest floor were included in survey data while specimens observed outside that range were included as incidentals. Photographs of each species observed were obtained when possible. JF returned to TBR for four days in August 2016 and haphazardly surveyed the cacao plantation, Canopy Trail, Ceiba Trail, Botarama Trail, Corteza Trail, and Hunter Trail. VES were conducted during the day or at night and the data were collected using the same methodology as in 2010.

SG and TP visited TBR for five days in 6-10 March 2017 and conducted surveys randomly during the day and night. Areas surveyed included the Canopy Trail, Ceiba Trail, Botarrama Trail, Corozo Trail and Corteza Trail; the cacao plantation; the garden areas adjacent to the primary lodging and administration area of TBR; and the eastern shoreline of the Sarapiquí River from the cacao plantation approximately to the suspension bridge. Methods included VES aided by the use of flashlights and limited active searching beneath cover. Photographs of all snakes and turtles, as well as all infrequently encountered frogs and lizards, were taken. For frequently encountered species, photographs were taken during all first encounters, with additional photos taken in cases of different age classes, or unique size, colour, or pattern variations.
In October 2017, 2018 and 2019 JF, SG, and TP returned to TBR. The 2017 team consisted of 19 people, while the 2018 and 2019 teams consisted of 23 people. In 2017, surveys were conducted on the Ajillo, Danta, and Hunter trails and in the area between the Tirimbina River and the Pavilion site. Surveys in 2018 and 2019 focused on the Ajillo Trail, Hunter Trail, Pavilion site, and Lagoon site. The Ajillo Trail and Hunter Trail surveys were conducted as $500 \mathrm{~m}$ transect surveys.

Timing of October 2017-2019 surveys followed that of the 2010 protocol outlined above and teams consisted of eight participants. Teams rotated among all sites. Each site was undisturbed for $36 \mathrm{~h}$ between successive surveys. Survey methods for the October 2017-2019 surveys followed that of the 2010 protocol, but the entire transect or area was searched during each survey period rather than subdividing the transects into $15 \mathrm{~m}$ segments.

In $2010 \mathrm{BH}$ and a field assistant conducted diurnal and nocturnal amphibian and reptile VES three times during the year in five line-transects in each of four secondary forests at TBR (Hilje and Aide 2012a). In 2019-2020, BH and a field assistant also monitored seven $8 \times 8 \mathrm{~m}$ forest leaf-litter plots. Two plots were adjacent to the Botarrama Trail, two adjacent to Cuculmeca Trail and one adjacent to Corozo, Ajillo, and Cacao Trails, respectively. Each plot was checked during the day by walking in the plot for $2 \mathrm{~h}$ and removing the leaf litter with a stick in both the wet season (July 2019) and the dry season (January 2020).

ERV has collected amphibian and reptile species records as notes and photographs, for 15 years. 
Data analysis. A subset of the survey data from GC and JK (unpublished data 2018-2019) was analyzed to estimate rank abundances, their 95\% confidence interval, and accumulative frequency for the species. This analysis included a total effort of 100 person-hours; $80 \mathrm{~h}$ of night surveys and $20 \mathrm{~h}$ of day surveys. The abundance was statistically analyzed using the $\mathrm{R}$ studio platform (Racine 2012). Rank abundances, their $95 \%$ confidence interval, and accumulative frequency were estimated using the "rankabundance" function of the R package "BiodiversityR" (Kindt and Coe 2005). Rank abundances were estimated separately for amphibians and reptiles. Each species was evaluated following the conservation criteria of IUCN (2020).

\section{Results}

Amphibian and reptile species richness. We recorded 52 amphibian and 78 reptile species in TBR (Table 1; Fig. 2). We documented species from all three amphibian orders: 47 species of Anura, one species of Gymnophiona, and four species of Caudata. Most species belong to the families Centrolenidae, Hylidae, Craugastoridae, and Ranidae. Craugastor was the most diverse genus with nine species, followed by Leptodactylus and Smilisca, both with four species, and Pristimantis, Lithobates, and Bolitoglossa with three species. We recorded species belonging to the three reptile orders present in Costa Rica. Crocodylia is represented by one species, while Testudines is represented by three species of semiaquatic turtles from three different families. The remainder of the reptile species belong to Squamata. Lizard diversity includes 26 species in 11 families, with most in the Dactyloidae. We recorded 47 snakes in five families. Dipsadidae was the most diverse with 22 species, followed by Colubridae with 18 species. Specimens were seen in a variety of habitats, such as primary forests, secondary forests, cacao plantation, open grassy areas, garden, riparian forests along streams, the Tirimbina River, permanent and temporal small ponds formed by river floods, and temporal swamps formed by water runoff (Table 1).

Amphibian and reptile abundances. From the rank abundance analysis, a total of 36 amphibian species and 26 reptile species were found, representing 69\% and 33\% of all the amphibians and reptiles documented in TBR, respectively (Tables 2, 3). Seven species of anurans, representing $>60 \%$ of total abundance, dominated the amphibian community. These species belong to the families Craugastoridae and Bufonidae, although Oophaga pumilio and Diasporus diastema are also among the most common species. Among reptiles, five species of lizards, in the families Dactyloidae, Teiidae, and Corytophanidae, and the snake Bothrops asper, dominated, comprising $>60 \%$ of total abundance.

Amphibian and reptile conservation status. According to the IUCN Red List (IUCN 2020), the conservation status of most of the amphibian species recorded in TBR is Least Concern (Table 1). Nevertheless, a few at-risk amphibian species are found in TBR. In particular, Cruzyiohyla sylviae, a recently recognized species of Phyllomedusidae, and Craugastor persimilis, are Vulnerable' due to habitat fragmentation, while the salamanders Bolitoglossa alvaradoi and Oedipina gracilis are Endangered because of habitat loss. The conservation status for most of the reptiles recorded in TBR is also Least Concern (IUCN 2020) (Table 1), with two exceptions. Although Bushmaster, Lachesis stenophrys, has not yet been evaluated by IUCN, it is an increasingly rare species given its requirements for relatively undisturbed forest (Savage 2002). The turtle Rhinoclemmys fune$r e a$, is Near Threatened due to a decline in the number of mature individuals in some areas of its distribution (IUCN 2020).

\section{Class Amphibia}

Order Gymnophiona

Family Dermophiidae Taylor, 1969

\section{Gymnopis multiplicata (Peters, 1874)}

Figure 2A

Material examined. COSTA RICA $\bullet 1 \hat{\jmath}$, adult; Heredia Province, Sarapiquí County, La Virgen, Tirimbina Biological Reserve; $010^{\circ} 25^{\prime} 01^{\prime \prime} \mathrm{N}, 084^{\circ} 07^{\prime} 27^{\prime \prime} \mathrm{W} ; 151 \mathrm{~m}$ elevation; 01 Aug. 2004; ERV leg.; UCR 23063. A single individual was observed and collected in the leaf litter of secondary forest.

Identification. A relatively large caecilian, maximum SVL $700 \mathrm{~mm}$ (Solorzano 2014). It is distinguished from other Costa Rican caecilians by its numerous secondary annuli, eyes that are not visible externally, and purple dorsal colour (Savage 2002).

Remarks. Although uncommon due to its fossorial habits, single individuals are often seen in secondary forests and gardens surrounding the facilities at TBR. This was an occasional sighting not observed in surveys.

Order Caudata

Family Plethodontidae Gray, 1850

\section{Bolitoglossa alvaradoi (Taylor, 1954)}

Figure 2B

Material examined. COSTA RICA $• 1$ adult; Heredia Province, Sarapiquí County, La Virgen, Tirimbina Biological Reserve; $010^{\circ} 25^{\prime} 01^{\prime \prime} \mathrm{N}, 084^{\circ} 07^{\prime} 27^{\prime \prime} \mathrm{W} ; 150 \mathrm{~m}$ alt.; specimen photographed. A single individual was found perched on low vegetation adjacent to a trail in primary forest.

Identification. A medium-sized salamander, maximum SVL $79 \mathrm{~mm}$ (Savage 2002). It is identified by fully webbed feet and dorsum dark brown to light olive with numerous grey or black blotches (Leenders 2016).

Remarks. An endangered and poorly known species that is supposedly a forest canopy dweller (Savage 2002). However, in TBR it has been found after heavy rains in 

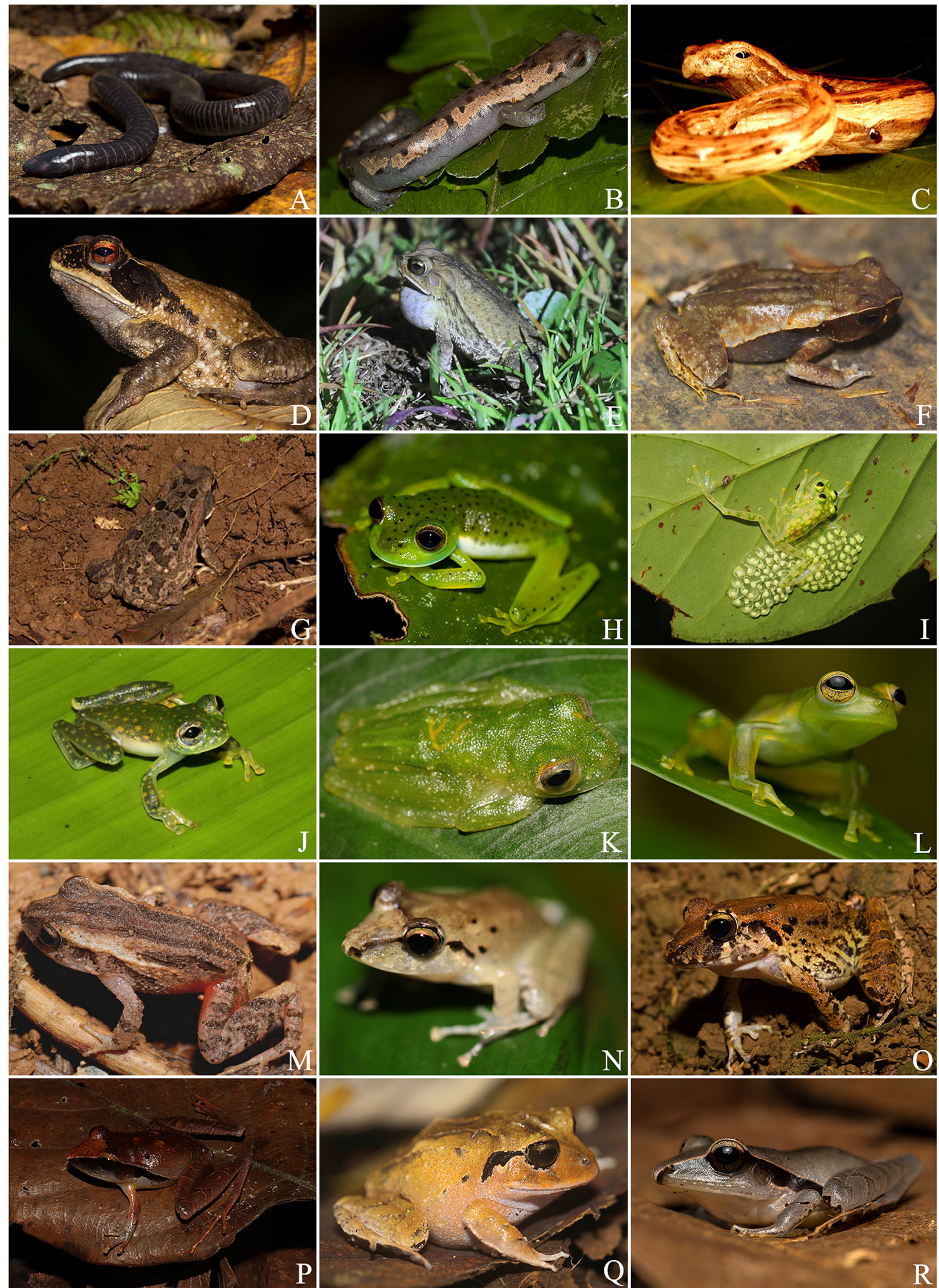

Figure 2. Species of amphibians occurring at TBR (photos by JF, JK, FT, SG and ERV). A. Gymnopis multiplicata. B. Bolitoglossa alvaradoi. C. Bolitoglossa striatula. D. Incilius melanochlorus. E. Incilius valliceps. F. Rhaebo haematiticus. G. Rhinella horribilis. H. Espadarana prosoblepon. I. Hyalinobatrachium valerioi. J. Sachatamia albomaculata. K. Teratohyla pulverata. L. Teratohyla spinosa. M. Craugastor bransfordii. N. Craugastor crassidigitus. O. Craugastor fitzingeri. P. Craugastor gollmeri. Q. Craugastor megacephalus. R. Craugastor mimus. 
Table 2. Rank abundances obtained for the amphibians at TBR generated from GC and JK surveys (2018-2019). Confidence intervals (CI) are shown.

\begin{tabular}{|c|c|c|c|c|c|c|}
\hline \multirow{2}{*}{ Species } & \multirow{2}{*}{ Rank } & \multirow{2}{*}{ Abundance } & \multirow{2}{*}{ Proportion } & \multicolumn{2}{|c|}{ Proportion Cl (95\%) } & \multirow{2}{*}{$\begin{array}{l}\text { Accumulative } \\
\text { frequency }\end{array}$} \\
\hline & & & & Lower & Upper & \\
\hline Craugastor fitzingeri & 1 & 89 & 10.4 & 2.0 & 18.8 & 10.4 \\
\hline Incilius melanochlorus & 2 & 83 & 9.7 & 3.7 & 15.7 & 20.1 \\
\hline Craugastor bransfordii & 3 & 74 & 8.6 & 2.4 & 14.9 & 28.7 \\
\hline Diasporus diastema & 4 & 73 & 8.5 & -6.6 & 23.7 & 37.3 \\
\hline Oophaga pumilio & 5 & 72 & 8.4 & 1.1 & 15.7 & 45.7 \\
\hline Rhinella horribilis & 6 & 72 & 8.4 & -4.4 & 21.2 & 54.1 \\
\hline Rhaebo haematiticus & 7 & 66 & 7.7 & 5.6 & 9.9 & 61.8 \\
\hline Lithobates vaillanti & 8 & 48 & 5.6 & -2.9 & 14.1 & 67.4 \\
\hline Lithobates warszewitschii & 9 & 45 & 5.3 & -0.2 & 10.7 & 72.7 \\
\hline Smilisca sordida & 10 & 45 & 5.3 & -1.0 & 11.6 & 77.9 \\
\hline Teratohyla spinosa & 11 & 28 & 3.3 & -3.8 & 10.3 & 81.2 \\
\hline Boana rutifela & 12 & 22 & 2.6 & -0.1 & 5.3 & 83.8 \\
\hline Craugastor megacephalus & 13 & 19 & 2.2 & -2.5 & 7.0 & 86.0 \\
\hline Craugastor persimilis & 14 & 19 & 2.2 & -0.5 & 4.9 & 88.2 \\
\hline Leptodactylus melanonotus & 15 & 15 & 1.8 & -0.2 & 3.8 & 90.0 \\
\hline Espadarana prosoblepon & 16 & 14 & 1.6 & -0.2 & 3.4 & 91.6 \\
\hline Pristimantis ridens & 17 & 14 & 1.6 & 0.0 & 3.2 & 93.2 \\
\hline Hyalinobatrachium fleischmanni & 18 & 10 & 1.2 & -2.3 & 4.7 & 94.4 \\
\hline Craugastor gollmeri & 19 & 8 & 0.9 & -0.7 & 2.6 & 95.3 \\
\hline Incilius valliceps & 20 & 8 & 0.9 & -1.0 & 2.9 & 96.3 \\
\hline Craugastor mimus & 21 & 7 & 0.8 & -0.4 & 2.0 & 97.1 \\
\hline Leptodactylus savagei & 22 & 5 & 0.6 & -0.4 & 1.5 & 97.7 \\
\hline Agalychnis callidryas & 23 & 4 & 0.5 & -0.1 & 1.0 & 98.1 \\
\hline Scinax elaeochroa & 24 & 3 & 0.4 & -0.5 & 1.2 & 98.5 \\
\hline Dendrobates auratus & 25 & 2 & 0.2 & -0.5 & 1.0 & 98.7 \\
\hline Pristimantis cerasinus & 26 & 2 & 0.2 & -0.3 & 0.7 & 98.9 \\
\hline Smilisca puma & 27 & 2 & 0.2 & -0.5 & 0.9 & 99.2 \\
\hline Hypopachus pictiventris & 28 & 1 & 0.1 & -0.1 & 0.4 & 99.3 \\
\hline Craugastor noblei & 29 & 1 & 0.1 & -0.1 & 0.4 & 99.4 \\
\hline Craugastor talamancae & 30 & 1 & 0.1 & -0.1 & 0.4 & 99.5 \\
\hline Dendropsophus phlebodes & 31 & 1 & 0.1 & -0.2 & 0.5 & 99.6 \\
\hline Lithobates taylori & 32 & 1 & 0.1 & -0.3 & 0.5 & 99.8 \\
\hline Scinax boulengeri & 33 & 1 & 0.1 & -0.1 & 0.4 & 99.9 \\
\hline Smilisca manisorum & 34 & 1 & 0.1 & -0.2 & 0.4 & 100.0 \\
\hline
\end{tabular}

primary and secondary forests perched on shrubs at 50 cm height. This was an occasional sighting not observed in surveys.

\section{Bolitoglossa striatula (Noble, 1918)}

Figure 2C

Material examined. COSTA RICA $\bullet 1 \hat{\jmath}$, adult; Heredia Province, Sarapiquí County, La Virgen, Tirimbina Biological Reserve; $010^{\circ} 25^{\prime} 01^{\prime \prime} \mathrm{N}, 084^{\circ} 07^{\prime} 27^{\prime \prime} \mathrm{W} ; 150 \mathrm{~m}$ alt.; specimen photographed. A single individual observed perched on low vegetation in secondary forest.

Identification. A small salamander, maximum SVL $130 \mathrm{~mm}$, identified by longitudinal light and dark brown stripes on a yellow dorsum and venter and by its fully webbed feet (Savage 2002).

Remarks. Although is an uncommon species in TBR, it can be found near temporal flooded areas and swamps. It also tolerates habitat alteration and may be found near the TBR facilities (Leenders 2016). This was an occasional sighting not observed in surveys.
Order Anura

Family Bufonidae Gray, 1825

\section{Incilius melanochlorus (Cope, 1877)}

Figure 2D

Material examined. COSTA RICA $\bullet 1$, adult; Heredia Province, Sarapiquí County, La Virgen, Tirimbina Biological Reserve; $010^{\circ} 24^{\prime} 5^{\prime \prime} \mathrm{N}, 084^{\circ} 07^{\prime} 29^{\prime \prime} \mathrm{W} ; 187 \mathrm{~m}$ alt.; 27 Oct. 2018; GC, JK leg.; UCR 23088. Specimen collected in riparian forest.

Identification. A medium to large toad, maximum SVL $103 \mathrm{~mm}$ (Savage 2002); however, individuals up to 115 $\mathrm{mm}$ SVL have been recorded in TBR (Hilje and Sanchez, 2015). It is recognized by its small triangular parotoid glands, well developed cranial crests, and dark brown dorsum and cream colour on its gular and chest area (Savage 2002, Leenders 2016).

Remarks. One of the most abundant species of TBR. A common forest dweller also found in leaf litter near the Sarapiquí River margins during the breeding season. 
Table 3. Rank abundances obtained for the reptiles at TBR generated from GC and JK surveys (2018-2019). Confidence intervals (CI) are shown.

\begin{tabular}{|c|c|c|c|c|c|c|}
\hline \multirow{2}{*}{ Species } & \multirow{2}{*}{ Rank } & \multirow{2}{*}{ Abundance } & \multirow{2}{*}{ Proportion } & \multicolumn{2}{|c|}{ Proportion Ci (95\%) } & \multirow{2}{*}{$\begin{array}{c}\text { Accumulative } \\
\text { frequency }\end{array}$} \\
\hline & & & & Lower & Upper & \\
\hline Anolis limifrons & 1 & 19 & 22.1 & 4.2 & 40.0 & 22.1 \\
\hline Holcosus festivus & 2 & 9 & 10.5 & 0.2 & 20.7 & 32.6 \\
\hline Bothrops asper & 3 & 7 & 8.1 & 1.2 & 15.1 & 40.7 \\
\hline Anolis humilis & 4 & 7 & 8.1 & -6.5 & 22.8 & 48.8 \\
\hline Basiliscus plumifrons & 5 & 6 & 7.0 & -2.2 & 16.1 & 55.8 \\
\hline Corytophanes cristatus & 6 & 4 & 4.7 & -5.5 & 14.8 & 60.5 \\
\hline Leptodeira septentrionalis & 7 & 4 & 4.7 & 0.1 & 9.2 & 65.1 \\
\hline Norops oxylophus & 8 & 4 & 4.7 & -1.2 & 10.5 & 69.8 \\
\hline Iguanaiguana & 9 & 3 & 3.5 & -0.5 & 7.5 & 73.3 \\
\hline Lepidoblepharis xanthostigma & 10 & 3 & 3.5 & -3.0 & 10.0 & 76.7 \\
\hline Porthidium nasutum & 11 & 3 & 3.5 & -2.8 & 9.8 & 80.2 \\
\hline Basiliscus vittatus & 12 & 2 & 2.3 & -4.6 & 9.2 & 82.6 \\
\hline Micrurus alleni & 13 & 2 & 2.3 & -1.8 & 6.5 & 84.9 \\
\hline Hemidactylus frenatus & 14 & 1 & 1.2 & -2.6 & 4.9 & 86.0 \\
\hline Bothriechis schlegelii & 15 & 1 & 1.2 & -0.9 & 3.3 & 87.2 \\
\hline Gonatodes albogularis & 16 & 1 & 1.2 & -2.3 & 4.6 & 88.4 \\
\hline Kinosternon leucostomum & 17 & 1 & 1.2 & -2.3 & 4.6 & 89.5 \\
\hline Lepidodactylus lugubris & 18 & 1 & 1.2 & -2.7 & 5.0 & 90.7 \\
\hline Ninia sebae & 19 & 1 & 1.2 & -2.6 & 4.9 & 91.9 \\
\hline Anolis capito & 20 & 1 & 1.2 & -2.6 & 4.9 & 93.0 \\
\hline Anolis lemurinus & 21 & 1 & 1.2 & -0.9 & 3.3 & 94.2 \\
\hline Rhadinea decorata & 22 & 1 & 1.2 & -0.9 & 3.3 & 95.3 \\
\hline Rhinoclemmys funerea & 23 & 1 & 1.2 & -2.6 & 4.9 & 96.5 \\
\hline Scincella cherriei & 24 & 1 & 1.2 & -0.9 & 3.3 & 97.7 \\
\hline Sibon nebulatus & 25 & 1 & 1.2 & -2.3 & 4.6 & 98.8 \\
\hline Thecadactylus rapicauda & 26 & 1 & 1.2 & -2.3 & 4.6 & 100.0 \\
\hline
\end{tabular}

Five to ten individuals were commonly found on leaf litter during VES in primary, secondary, and riparian forests, and in cacao plantations (Table1).

\section{Incilius valliceps (Wiegmann, 1833)}

Figure 2E

Material examined. COSTA RICA $\bullet 1$, adult; Heredia Province, Sarapiquí County, La Virgen, Tirimbina Biological Reserve; $010^{\circ} 24^{\prime} 56^{\prime \prime} \mathrm{N}, 084^{\circ} 07^{\prime} 21^{\prime \prime} \mathrm{W}$; $145 \mathrm{~m}$ alt.; 01 Feb. 2019; JK, GC leg.; UCR 23197. Specimen collected in an open grassy area.

Identification. A medium-sized toad, maximum SVL 76 $\mathrm{mm}$, with a triangular parotid gland and a unique lateral dark brown stripe with numerous light-yellow, pointy warts, and well-developed cranial crests (Savage, 2002).

Remarks. This leaf-litter species was known to occur only in the northern parts of Costa Rica; however, it was recently recorded in open areas adjacent to wet forests of the TBR, representing a new life zone for this species (Klank et al. 2020). Single individuals were observed on the ground during VES in open grassy areas (Table 1).

Family Centrolenidae Taylor, 1951

\section{Cochranella granulosa (Taylor, 1949)}

Material examined. COSTA RICA • 1 juvenile; Heredia Province, Sarapiquí County, La Virgen, Tirimbina Biological Reserve; $010^{\circ} 24^{\prime} 24^{\prime \prime} \mathrm{N}, 084^{\circ} 07^{\prime} 45^{\prime \prime} \mathrm{W} ; 144 \mathrm{~m}$ alt.; 23 Mar. 2019; JK, GC, Kimberly Castro leg.; specimen identified based on field observations, egg clutches, and calls. Specimen observed perched on a tree in riparian forest.

Identification. A small uniform dark green frog. Maximum SVL $29 \mathrm{~mm}$, with unique dorsal colour pattern showing scattered black spots and white lips (Savage 2002).

Remarks. An arboreal species commonly observed calling at night on riverine vegetation throughout TBR mostly after afternoon heavy rains. Egg masses are usually observed on leaves. Several males can be listened singing on riparian forests; however, males perch high on the vegetation and are not commonly seen during VES (Table 1).

Family Craugastoridae Hedges, Duellman \& Heinicke, 2008

\section{Craugastor bransfordii (Cope, 1885)}

Figure 2M

Material examined. COSTA RICA • $1 \hat{\jmath}$, Adult; Heredia Province, Sarapiquí County, La Virgen, Tirimbina Biological Reserve; 010²4'56"N, 08407'14"W; $163 \mathrm{~m}$ alt.; 05 Oct. 2018; GC, JK leg.; UCR 23071. Specimen observed on leaf litter in secondary forest.

Identification. A small, common, brown, leaf-litter frog, maximum SVL $23 \mathrm{~mm}$, with distinctive tubercles on hand and feet (Savage 2002). 
Remarks. This is one of the most common leaf-litter frogs at TBR, easily found in shaded ground and deep leaf-litter habitats throughout the reserve. This species has several different colour morphs that vary from a solid dark brown or black to a stripped creamy dorsum. Five to ten individuals were commonly found on leaf litter during VES in different forest habitats and open grassy areas (Table 1).

\section{Craugastor megacephalus (Cope, 1875)}

Figure 2Q

Material examined. COSTA RICA $\bullet 1 \hat{\jmath}$, juvenile; Heredia Province, Sarapiquí County, La Virgen, Tirimbina Biological Reserve; 010²4'51"N, 08407'12"W; $192 \mathrm{~m}$ alt.; 05 Oct. 2018; GC, JK leg.; UCR 23055. Specimen found in leaf litter in primary forest.

Identification. A leaf-litter dweller with a distinctive broad head, expanded toe disks lacking webbing, maximum SVL $43 \mathrm{~mm}$, usually with a uniform yellow dorsum (Savage 2002).

Remarks. A quiet common species observed in forests at TBR during the day that relies on camouflage to avoid predators. Single individuals were found on leaf litter during VES in primary and secondary forests (Table 1).

\section{Craugastor mimus (Taylor, 1955)}

Figure 2R

Material examined. COSTA RICA • $1 \hat{\partial}$, adult; Heredia Province, Sarapiquí County, La Virgen, Tirimbina Biological Reserve; $010^{\circ} 24^{\prime} 54^{\prime \prime} \mathrm{N}, 084^{\circ} 07^{\prime} 07^{\prime \prime} \mathrm{W}$; $178 \mathrm{~m}$ alt.; 05 Oct. 2018; GC, JK leg.; UCR 23108. Specimen observed on leaf litter in primary forest.

Identification. A long-legged, leaf-litter dwelling frog with a uniform grey dorsum and characteristic fringed toes, maximum SVL $58 \mathrm{~mm}$ (Savage 2002).

Remarks. A nocturnal species commonly found on the forest floor or perched on low vegetation $(<50 \mathrm{~cm})$ at TBR. Individuals from TBR are the largest reported for this species, reaching SVL $72 \mathrm{~mm}$ (Hilje and Sanchez 2015). Single individuals were found on leaf litter during VES in primary and secondary forests (Table 1).

Family Dendrobatidae Cope, 1865

\section{Oophaga pumilio (Schmidt, 1857)}

Figure 3F

Material examined. COSTA RICA $\bullet 1$, adult; Heredia Province, Sarapiquí County, La Virgen, Tirimbina Biological Reserve; $010^{\circ} 24^{\prime} 40^{\prime \prime} \mathrm{N}, 084^{\circ} 07^{\prime} 18^{\prime \prime} \mathrm{W} ; 152 \mathrm{~m}$ alt.; 05 Oct. 2018; GC, JK leg.; UCR 23073. Specimen observed on leaf litter of secondary forest.

Identification. A brightly colored small frog, maximum SVL $24 \mathrm{~mm}$, with red dorsum and hindlimbs varying from red, black, or blue (Savage 2002).

Remarks. One of the most abundant amphibians in TBR commonly found on leaf litter. At TBR, individuals usually have a red dorsum with blue hindlimbs, feet, and hands that make them easy to detect. This species is highly attractive for environmental education and tourism activities. Five to ten individuals were commonly found on the ground during VES in different forested habitats, cacao plantation, and open grassy areas (Table 1).

Family Eleutherodactylidae Lutz, 1954

\section{Diasporus diastema (Cope, 1875)}

Figure $2 \mathrm{H}$

Material examined. COSTA RICA • $1 \hat{\jmath}$, Juvenile; Heredia Province, Sarapiquí County, La Virgen, Tirimbina Biological Reserve; 010²4'48"N, 08407'17"W; 159 m alt.; 05 Oct. 2018; GC, JK leg.; UCR 23104. Specimen observed perched on vegetation in secondary forest.

Identification. A small frog, maximum SVL $24 \mathrm{~mm}$, with dorsal colour patterns that vary from yellow and pink to gray; easy to identify by its intense, single, "tink" call and rounded toe disks (Savage 2002; Hilje and Aide 2012b).

Remarks. A common nocturnal species that can be heard at night, or during the day after heavy rains, singing while perched on low vegetation $(40-200 \mathrm{~cm})$ in different forested habitats in TBR. This species is not commonly observed during VES due to its small size and secretive habits.

Family Phyllomedusidae Gunther, 1958

\section{Agalychnis callidryas (Cope, 1862)}

Figure 2I

Material examined. COSTA RICA • $1 \hat{\jmath}$, adult; Heredia Province, Sarapiquí County, La Virgen, Tirimbina Biological Reserve; $010^{\circ} 24^{\prime} 43^{\prime \prime} \mathrm{N}, 084^{\circ} 07^{\prime} 18^{\prime \prime} \mathrm{W} ; 155 \mathrm{~m}$ alt.; 05 Oct. 2018; GC, JK leg.; UCR 23064. Specimen observed perched on a tree branch in a swampy area.

Identification. A medium-sized frog, maximum SVL 77 $\mathrm{mm}$, with large bright red eyes, green dorsum, and characteristic blue flanks with yellowish vertical lines (Savage 2002).

Remarks. An arboreal frog commonly found on vegetation surrounding swamps and temporary pools at TBR. Given its bright eyes and coloration, it is a flagship species for environmental education and tourism. Single individuals were observed during VES in forested and swampy habitats (Table 1).

Family Hylidae Rafinesque, 1815

\section{Scinax boulengeri (Cope, 1887)}

Figure 40

Material examined. COSTA RICA • $1 \hat{\jmath}$, adult; Heredia Province, Sarapiquí County, La Virgen, Tirimbina Biological Reserve; $010^{\circ} 24^{\prime} 45^{\prime \prime} \mathrm{N}, 084^{\circ} 07^{\prime} 18^{\prime \prime} \mathrm{W} ; 159 \mathrm{~m}$ alt.; 03 Mar. 2020; JK, GC leg.; UCR 23373. Specimen observed perched on a tree branch in a swampy area. 


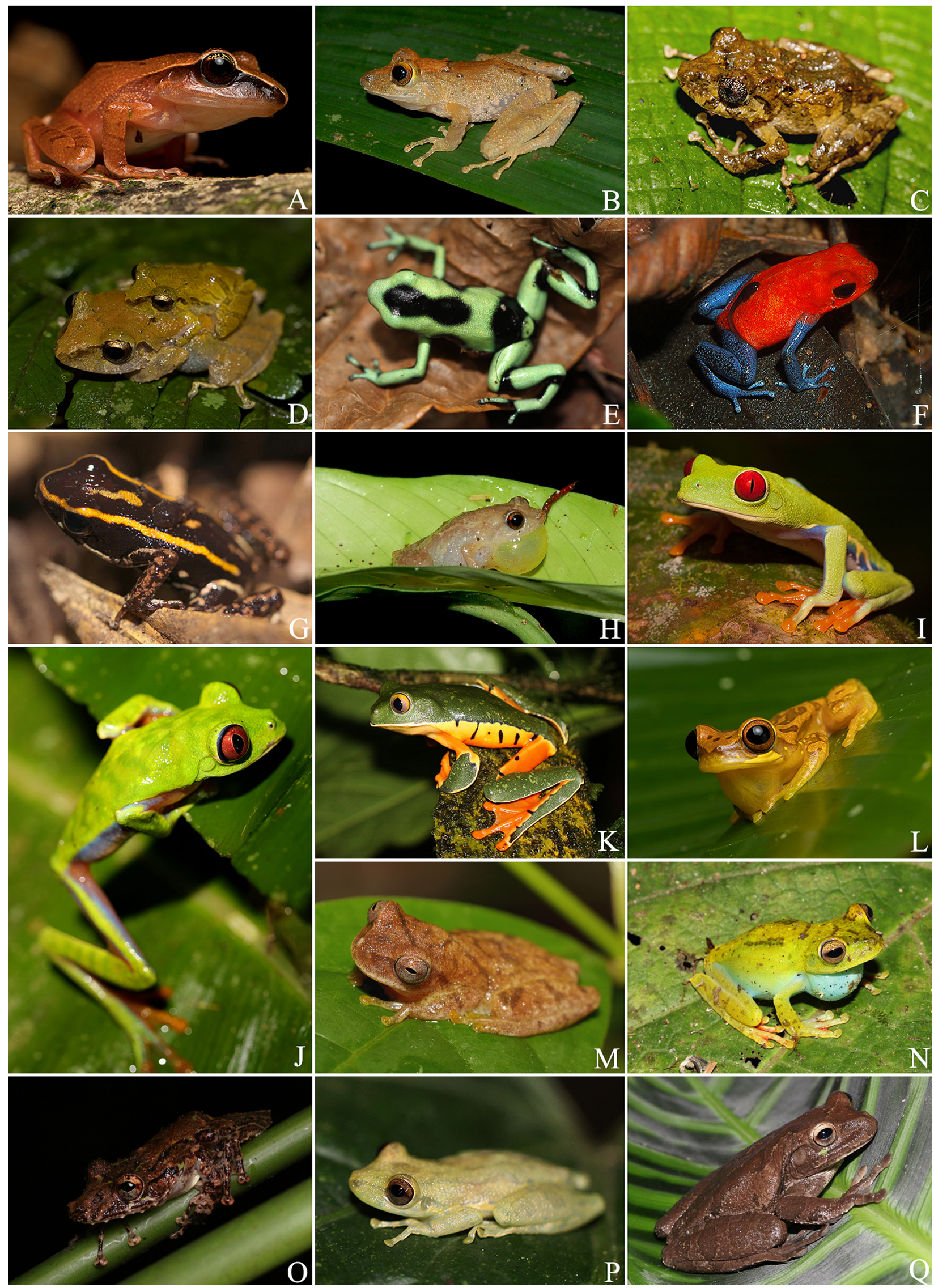

Figure 3. Species of amphibians occurring at TBR (photos by JF, JK, FT, SG and ERV). A. Craugastor noblei. B. Pristimantis cerasinus. C. Pristimantis cruentus. D. Pristimantis ridens. E. Dendrobates auratus. F. Oophaga pumilio. G. Phyllobates lugubris H. Diasporus diastema. I. Agalychnis callidryas. J. Agalychnis saltator. K. Cruziohyla sylviae. L. Dendropsophus ebraccatus. M. Dendropsophus phlebodes. N. Boana rufitela. O. Scinax boulengeri. P. Scinax elaeochroa. Q. Smilisca manisorum. 

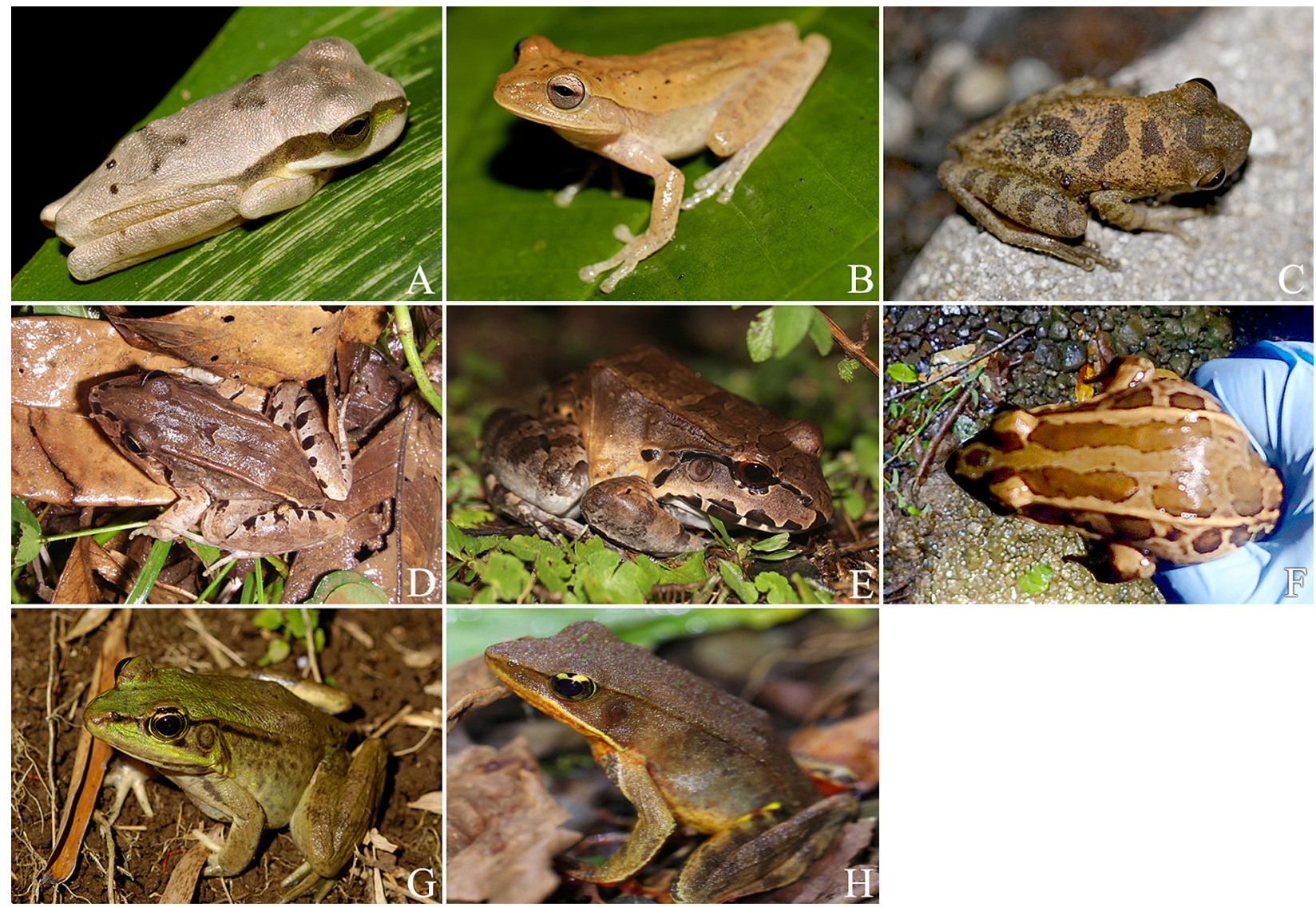

Figure 4. Species of amphibians occurring at TBR (photos by JF, JK, FT, SG and ERV, D. by H. Fabian). A. Smilisca phaeota. B. Smilisca puma. C. Smilisca sordida. D. Leptodactylus poecilochilus. E. Leptodactylus savagei. F. Lithobates taylori. G. Lithobates vaillanti. H. Lithobates warszewitschii.

Identification. A medium-sized frog, maximum SVL 53 $\mathrm{mm}$, with a distinctive strongly tuberculated body and yellow-green bars on the posterior thighs (Savage 2002).

Remarks. A nocturnal arboreal species commonly found in swampy areas and temporary ponds at TBR where several scattered males sing from vegetation adjacent to the water bodies. One to five individuals were commonly observed after heavy rains during VES in forested and swampy areas (Table 1).

Family Microhylidae Günther, 1858

\section{Hypopachus pictiventris (Cope, 1886)}

Material examined. COSTA RICA • 1 juvenile; Heredia Province, Sarapiquí County, La Virgen, Tirimbina Biological Reserve; $010^{\circ} 24^{\prime} 34^{\prime \prime} \mathrm{N}, 084^{\circ} 07^{\prime} 05^{\prime \prime} \mathrm{W}$; $185 \mathrm{~m}$ alt. 27 Mar. 2018; GC, JK leg.; UCR 23109. Specimen collected on leaf litter in primary forest.

Identification. A small to medium-sized frog, maximum SVL $38 \mathrm{~mm}$. It is recognized by a dark brown dorsum and white blotches on dark brown venter, smooth skin, and a small, narrow head (Savage 2002).

Remarks. A species believed to be common in leaf litter, but it was rarely seen at TBR because of its fossorial and secretive behavior. A single individual was observed during VES in primary forests (Table 1).
Family Ranidae Batsch, 1796

\section{Lithobates warszewitschii (Schmidt, 1857)}

Figure $4 \mathrm{H}$

Material examined. COSTA RICA • 1 Juvenile; Heredia Province, Sarapiquí County, La Virgen, Tirimbina Biological Reserve; $010^{\circ} 24^{\prime} 40^{\prime \prime} \mathrm{N}, 084^{\circ} 07^{\prime} 19^{\prime \prime} \mathrm{W} ; 154 \mathrm{~m}$ alt.; 05 Mar. 2018; GC, JK leg.; UCR 23070. Specimen observed on leaf litter in secondary forest.

Identification. A medium-sized frog, maximum SVL 63 $\mathrm{mm}$. It is identified by brown dorsum and bright yellow spots on the inner thigh, a pair of dorsolateral folds, and a white stripe on its upper lip.

Remarks. A common leaf-litter dweller throughout TBR found on trails during the day and night. The only species of the family in Costa Rica that inhabits forest floors instead of water bodies (Savage 2002). One to five individuals were commonly observed during VES in forested and open habitats.

Class Reptilia

Order Crocodylia

Family Alligatoridae Gray, 1844

Caiman crocodilus (Linnaeus, 1758)

Figure 5A 

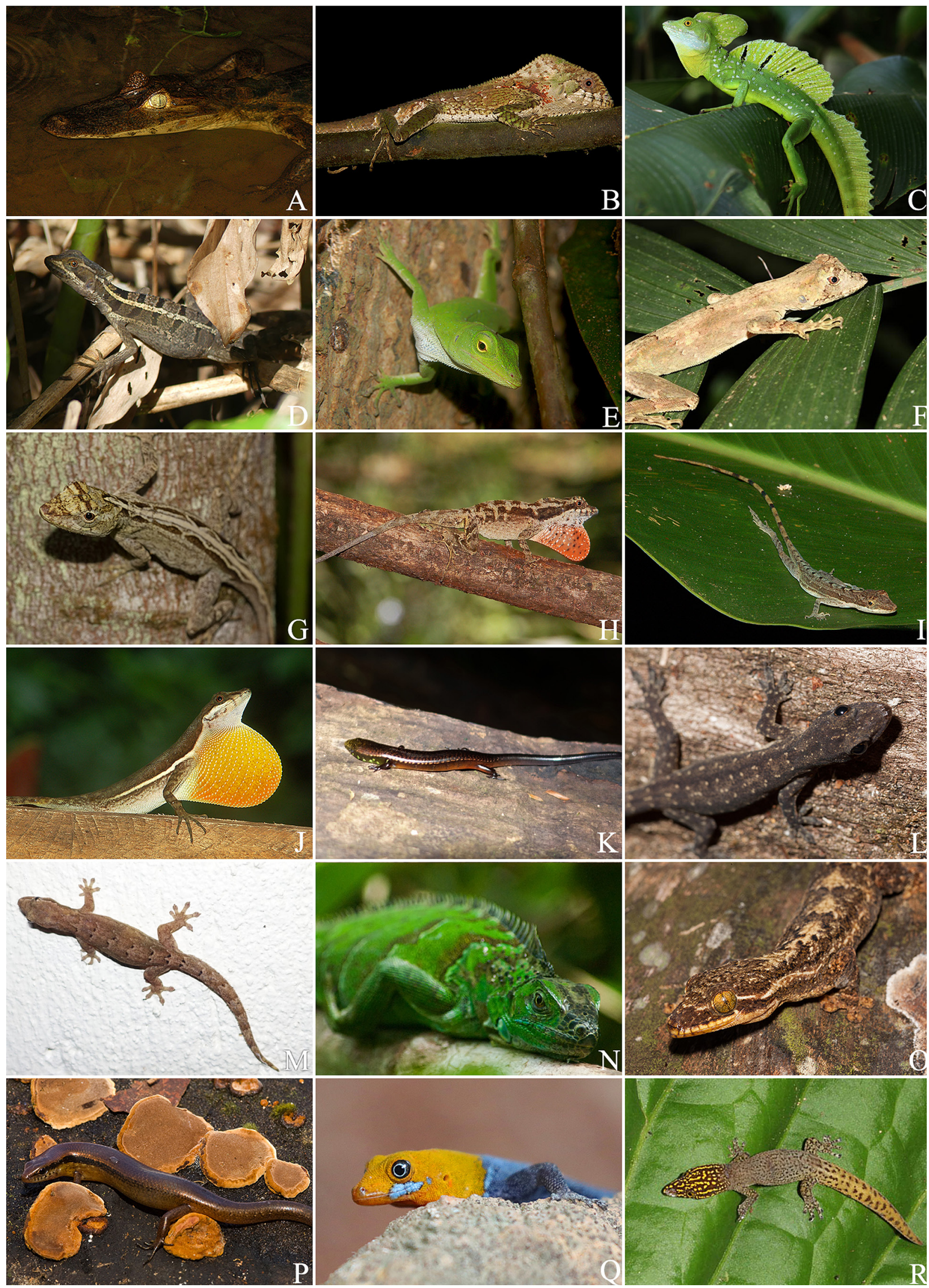

Figure 5. Species of reptiles occurring at TBR (photos by JF, JK, FT, SG and ERV). A. Caiman crocodilus. B. Corytophanes cristatus. C. Basiliscus plumifrons. D. Basiliscus vittatus. E. Anolis biporcatus. F. Anolis capito. G. Anolis humilis. H. Anolis lemurinus. I. Anolis limifrons. J. Anolis oxylophus. K. Diplogossus bilobatus. L. Hemidactylus frenatus. M. Lepidodactylus lugubris. N. Iguana iguana. O. Thecadactylus rapicauda. P. Scincella cherriei. Q. Gonatodes albogularis. R. Sphaerodactylus homolepis. 
Material examined. COSTA RICA • 1 juvenile; Heredia Province, Sarapiquí County, La Virgen, Tirimbina Biological Reserve; $010^{\circ} 24^{\prime} 24^{\prime \prime} \mathrm{N}, 084^{\circ} 07^{\prime} 18^{\prime \prime} \mathrm{W} ; 158 \mathrm{~m}$ alt.; 23 Mar. 2019; JK, GC, Kimberly Castro leg.; specimen observed and photographed in a pond located in the primary forest.

Identification. This species differs from the American crocodile (Crocodylus acutus) by the absence of a finger web, the presence of a high cranial crest in front of the eyes, maxillary teeth hidden when the mouth is closed, and smooth grey dorsal scales; maximum SVL $2500 \mathrm{~mm}$ (Savage 2002).

Remarks. This is the first report for TBR, and it is a juvenile of $\mathrm{SVL}=352 \mathrm{~mm}$ found in a permanent pond. It was found during VES in primary forests (Table 1). The species is commonly observed in water bodies surrounding TBR.

Order Squamata

Suborder Sauria

Familia Corytophanidae Fitzinger, 1843

\section{Corytophanes cristatus (Merrem, 1820)}

Figure 5B

Material examined. COSTA RICA • $1 \hat{\sigma}$, adult; Heredia Province, Sarapiquí County, La Virgen, Tirimbina

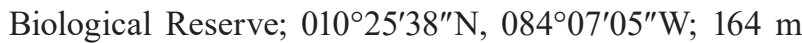
alt.; 23 Mar. 2019; JK, GC, Kimberly Castro leg.; UCR 23252. Specimen found perched on a tree branch in secondary forest.

Identification. A medium-sized lizard species, maximum SVL $120 \mathrm{~mm}$, with a characteristic helmet-like head which joins a medial dorsal cephalic crest (Savage 2002).

Remarks. A common arboreal species at TBR usually found in sit-and-wait position waiting for prey (Savage 2002). It lays eggs on the ground and remains still when manipulated as a defense mechanism, making it popular for tourist photography (Andrews 1979; Savage 2002). Single individuals were observed during VES in secondary forests (Table 1).

Family Dactyloidae Fitzingeri, 1843

\section{Anolis biporcatus (Wiegmann, 1834)}

Figure 5E

Material examined. COSTA RICA • 1 adult; Heredia Province, Sarapiquí County, La Virgen, Tirimbina Biological Reserve; $010^{\circ} 25^{\prime} 38^{\prime \prime} \mathrm{N}, 084^{\circ} 07^{\prime} 05^{\prime \prime} \mathrm{W} ; 160 \mathrm{~m}$ alt.; specimen observed and photographed in the field. Specimen found perched on vegetation in secondary forest.

Identification. A large, short-legged anole with distinctive strongly keeled ventral scales; maximum SVL 99 $\mathrm{mm}$. This species is uniformly light green but can turn dark brown when perturbed (Savage 2002).

Remarks. One of the largest anoles found perched on trees in TBR forests. As a defense mechanism, its skin peels off, but it recovers quickly. A single individual observed during VES in secondary forests (Table 1).

Family Diploglossidae Bocourt ,1873

\section{Diplogossus bilobatus (O’Shaughnessy, 1874) Figure 5K}

Material examined. COSTA RICA • 1 Adult; Heredia Province, Sarapiquí County, La Virgen, Tirimbina Biological Reserve; $010^{\circ} 25^{\prime} 38^{\prime \prime} \mathrm{N}, 084^{\circ} 07^{\prime} 27^{\prime \prime} \mathrm{W} ; 150 \mathrm{~m}$ alt.; specimen observed and photographed in the field. Specimen observed on leaf litter in secondary forest.

Identification: A medium-sized galliwasp lizard, maximum SVL $99 \mathrm{~mm}$, with dark green dorsum colour and black bars alternating with light yellow (Savage 2002). Easy to identify by its short limbs, skin covered with small keeled cycloid scales, claws hidden within a scaly sheath, and an enlarged interoccipital scale (Savage 2002).

Remarks. It was rarely seen at TBR due to its secretive and semi-fossorial habits. This was an occasional sighting not observed in surveys.

Familia Iguanidae Oppel, 1811

\section{Iguana iguana (Linnaeus, 1758)}

Figure 5N

Material examined. COSTA RICA -1 adult; Heredia Province, Sarapiquí County, La Virgen, Tirimbina Biological Reserve; $010^{\circ} 24^{\prime} 56^{\prime \prime} \mathrm{N}, 084^{\circ} 07^{\prime} 17^{\prime \prime} \mathrm{W} ; 143 \mathrm{~m}$ alt.; 27 Oct. 2018; GC, JK leg.; specimen observed and photographed in the field. Specimen observed perched on a tree adjacent to the Sarapiquí River.

Identification. This is the largest iguanid lizard in the country, maximum SVL $580 \mathrm{~mm}$. It is identified by a circular enlarged smooth scale below the tympanum, green dorsum and venter, and a dorsal crest (Savage 2002). Adult males change their colour to a golden yellow or orange during the breeding season (Lenders 2019).

Remarks. A common species usually found perched on tall trees on riverine vegetation along the Sarapiquí River. Some males can exceed $1.5 \mathrm{~m}$ in total length. Juveniles can be seen perched on low vegetation. One to five individuals were commonly observed during VES in gardens and riparian forests (Table 1).

Family Phyllodactylidae Gamble, Bauer, Greenbaum \& Jackman 2008

\section{Thecadactylus rapicauda (Houttuyn, 1782) \\ Figure 50}

Material examined. COSTA RICA $\bullet 1 \hat{\jmath}$, adult; Heredia Province, Sarapiquí County, La Virgen, Tirimbina Biological Reserve; $010^{\circ} 24^{\prime} 41^{\prime \prime} \mathrm{N}, 084^{\circ} 07^{\prime} 19^{\prime \prime} \mathrm{W} ; 151 \mathrm{~m}$ alt.; 04 Oct. 2019; GC, JK leg.; UCR 23257. Specimen observed on a tree buttress in the cacao plantation.

Identification. The largest species of gecko in Costa Rica, maximum SVL $126 \mathrm{~mm}$. It is identified by its uniform grey dorsum, large digital pads, digits enclosed in 
a well-developed fleshy web, and retractile claws on fingers and toes (Savage 2002).

Remarks. An arboreal nocturnal species with a broad tail, extensive lamellae and vertical pupils. It is observed in broad-stemmed trees such as figs, but also in open areas and in human-built structures (e.g. roofs and fences) adjacent to forests at TBR. Like other members of the family, it vocalizes sporadically. This was an occasional sighting not observed in surveys.

Family Scincidae Gray, 1825

\section{Scincella cherriei (Cope, 1893)}

Figure 5P

Material examined. COSTA RICA • 1 juvenile; Heredia Province, Sarapiquí County, La Virgen, Tirimbina Biological Reserve; $010^{\circ} 24^{\prime} 56^{\prime \prime} \mathrm{N}, 084^{\circ} 07^{\prime} 12^{\prime \prime} \mathrm{W} ; 182 \mathrm{~m}$ alt.; 27 Oct. 2018; GC, JK leg.; UCR 23092. Specimen found on leaf litter in secondary forest.

Identification. A small, diurnal, leaf-litter dwelling skink, maximum SVL $68 \mathrm{~mm}$ (Savage 2002). It is distinguished from other skinks by the presence of white colour on the upper lip, bronze dorsum, and by lacking enlarged nuchal scales (Savage 2002; Köhler 2008).

Remarks. A diurnal species found on forest floors with abundant leaf litter such as cacao plantations and gaps in secondary forests at TBR. A common species at TBR but difficult to find due to its fast escape behavior and hiding under leaf litter to avoid predation. Single individuals commonly found during VES in secondary forests (Table 1).

Family Sphaerodactylidae Underwood, 1954

\section{Gonatodes albogularis (Duméril \& Bibron, 1836) Figure 5Q}

Material examined. COSTA RICA • $1 \hat{\partial}$, adult; Heredia Province, Sarapiquí County, La Virgen, Tirimbina Biological Reserve; $010^{\circ} 24^{\prime} 41^{\prime \prime} \mathrm{N}, 084^{\circ} 07^{\prime} 18^{\prime \prime} \mathrm{W} ; 155 \mathrm{~m}$ alt.; 05 Oct. 2018; GC, JK leg.; UCR 23074. Specimen found on a tree trunk in the garden.

Identification. A small, diurnal, arboreal gecko, maximum SVL $48 \mathrm{~mm}$. Males with a unique bright orange head, black to gray-brown bodies, and blue lateral spots. Females and juveniles with a creamy-white dorsum with small brown dots. It differs from other members of the family by lacking retractile claws and enlarged terminal scales on digits (Savage 2002).

Remarks. An arboreal and ground-dwelling species commonly found in human infrastructure but also on tree buttresses and trunks at TBR. Single individuals commonly found during VES in garden (Table 1).

\section{Sphaerodactylys homolepis (Cope, 1886)}

Figure 5R

Material examined. COSTA RICA • 1 $\partial$, adult; Heredia Province, Sarapiquí County, La Virgen, Tirimbina Biological Reserve; $010^{\circ} 24^{\prime} 41^{\prime \prime} \mathrm{N}, 084^{\circ} 07^{\prime} 18^{\prime \prime} \mathrm{W} ; 155 \mathrm{~m}$ alt.;
05 Oct. 2018; GC, JK leg.; UCR 23074. Specimen found on a tree buttress in the secondary forest.

Identification. A small semi-arboreal diurnal gecko, maximum SVL $33 \mathrm{~mm}$. Adults can be easily distinguished by its grey dorsum and a unique striped head, usually with yellow spots. Juveniles have four black dorsal bands with cream margins (Savage 2002).

Remarks. One of the most beautiful geckos in Costa Rica, although difficult to observe at TBR due to its secretive behavior. This was an occasional sighting not observed in surveys.

Family Teiidae Gray, 1827

\section{Holcosus festivus (Lichtenstein \& Martens, 1856)} Figure 6A

Material examined. COSTA RICA • 1 juvenile; Heredia Province, Sarapiquí County, La Virgen, Tirimbina Biological Reserve; $010^{\circ} 24^{\prime} 36^{\prime \prime} \mathrm{N}, 084^{\circ} 06^{\prime} 53^{\prime \prime} \mathrm{W} ; 183 \mathrm{~m}$ alt.; 05 Oct. 2018; GC, JK leg.; UCR 23095. Specimen found on leaf litter of secondary forest.

Identification. A medium-sized lizard, maximum SVL $129 \mathrm{~mm}$ (Savage 2002). Juveniles with a distinctive lightblue dorsal stripe which disappears at maturity. Adults with two or three distinctive yellow, dashed, longitudinal stripes (Savage 2002).

Remarks. A commonly observed lizard in sunny, open areas at TBR. This species looks actively for food during the day and hides in burrows at night. One to five individuals commonly observed during VES in secondary forests (Table 1).

Family Xantusiidae Bair, 1858

\section{Lepidophyma flavimaculatum (Duméril, 1851) Figure 6C}

Material examined. COSTA RICA $\bullet ~ 1 q$, adult; Heredia Province, Sarapiquí County, La Virgen, Tirimbina Biological Reserve; $010^{\circ} 25^{\prime} 04^{\prime \prime} \mathrm{N}, 084^{\circ} 07^{\prime} 08^{\prime \prime} \mathrm{W} ; 148 \mathrm{~m}$ alt.; 04 Oct. 2019; JK, GC leg.; UCR 23197. Specimen found outside of its burrow on a hillside trail in the primary forest.

Identification. A medium-sized, nocturnal lizard, maximum SVL $101 \mathrm{~mm}$ (Savage 2002). Easy to identify by the contrast between its smooth head and tuberculated body and by many small yellow dots on its dark-brown dorsum (Savage 2002).

Remarks. A nocturnal species often found outside of its burrow on hillsides of trails at TBR. It is a parthenogenetic species; all individuals are females. Single individuals were found on the ground during VES in primary forests (Table 1).

Suborder Serpentes

Family Boidae Gray, 1825

\section{Boa imperator (Daudin, 1803)}

Figure 6D 


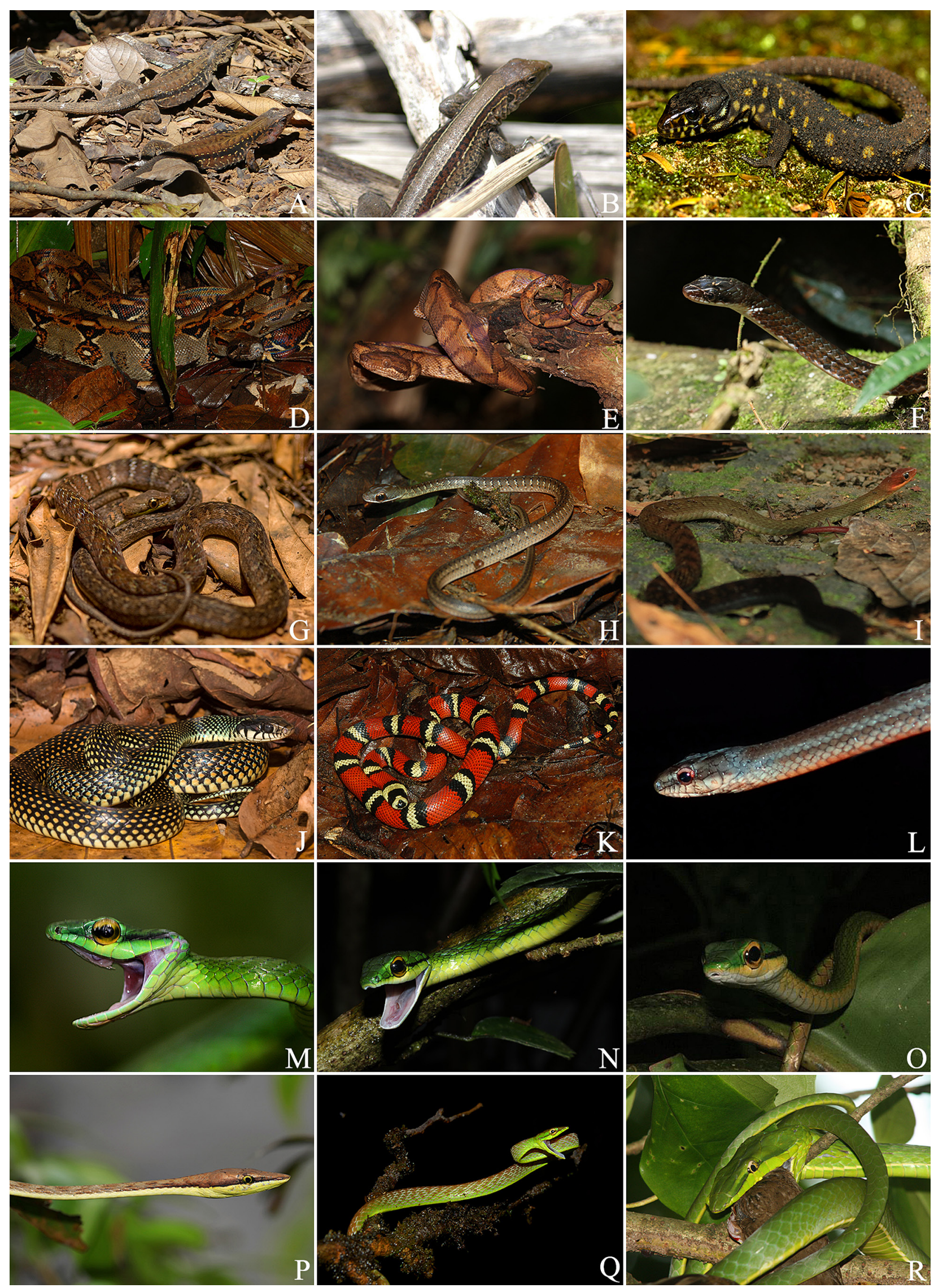

Figure 6. Species of reptiles occurring at TBR (photos by JF, JK, FT, SG and ERV). A. Holcosus festivus. B. Holcosus quadrilineatus. C. Lepidophyma flavimaculatum. D. Boa imperator. E. Corallus annulatus. F. Chironius grandisquamis. G. Dendrophidion apharocybe. H. Dendrophidion percarinatum. I. Dendrophidion rufiterminorum. J. Drymobius margaritiferus. K. Lampropeltis abnorma. L. Mastigodryas melanolomus. M. Leptophis ahaetulla. N. Leptophis depressirostris. O. Leptophis nebulosus. P. Oxybelis aeneus. Q. Oxybelis brevirostris. R. Oxybelis fulgidus. 
Material examined. COSTA RICA • 1 $\delta$, adult; Heredia Province, Sarapiquí County, La Virgen, Tirimbina Biological Reserve; $010^{\circ} 25^{\prime} 02^{\prime \prime} \mathrm{N}, 084^{\circ} 07^{\prime} 31^{\prime \prime} \mathrm{W} ; 153 \mathrm{~m}$ alt.; 29 Sep. 2018; Karolina Islera leg.; UCR 23058. Specimen found on the ground of secondary forest.

Identification. This is the largest and most robust species of this family in Costa Rica, maximum SVL 300 $\mathrm{cm}$. In contrast to other species of the family, this species lacks labial pits and has small smooth scales on its head (Solórzano 2004).

Remarks. This is a common species observed at TBR, basking in open sunny areas in forests. Single individuals were found during VES in secondary forest and open grassy areas.

Familia Colubridae Oppel, 1811

\section{Mastigodryas melanolomus (Cope, 1868)}

Figure 6L

Material examined. COSTA RICA • $1 \hat{\jmath}$, adult; Heredia Province, Sarapiquí County, La Virgen, Tirimbina Biological Reserve; $010^{\circ} 25^{\prime} 00^{\prime \prime} \mathrm{N}, 084^{\circ} 07^{\prime} 26^{\prime \prime} \mathrm{W} ; 116 \mathrm{~m}$ alt.; 05 Oct. 2018; JK, GC leg.; UCR 23050. Specimen found on the ground of secondary forest.

Identification. A medium-sized snake, maximum SVL $1400 \mathrm{~mm}$ (Solórzano 2004). This species has 17 scale rows at midbody and a pair of cream lateral lines on a dark-brown dorsum. Juveniles have large, dark-brown spots on a cream background, so they are often confused with other species (Savage 2002).

Remarks. A very nervous snake that strikes when disturbed. One of the most common diurnal snake species at TBR, usually observed on trails and close to water bodies. Single individuals were found during VES in secondary and riverine forests.

Familia Dipsadidae Bonaparte 1838

\section{Dipsas articulata (Cope, 1868)}

Figure $7 \mathrm{G}$

Material examined. COSTA RICA • $1 \hat{\jmath}$, adult; Heredia Province, Sarapiquí County, La Virgen, Tirimbina Biological Reserve; $010^{\circ} 02^{\prime} 57^{\prime \prime} \mathrm{N}, 084^{\circ} 07^{\prime} 18^{\prime \prime} \mathrm{W} ; 142 \mathrm{~m}$ alt.; 19 Jan. 2019; JK, GC, Kimberly Castro leg.; UCR 23193. Species found perched on a tree in the primary forest.

Identification. A small, snail-eating snake, maximum SVL $750 \mathrm{~mm}$, easily identified by its dorsal black and white rings with reddish edges. It has large eyes, several small black spots on the head, and lacks the mental groove present in other Dipsas species (Solórzano 2004).

Remarks. A nocturnal uncommon species at TBR which was observed moving slowly on low vegetation probably looking for terrestrial snails, its main diet. A single individual observed only one time during VES in the primary forest.

\section{Ninia sebae (Duméril, Bibron \& Duméril, 1854)}

Figure 70

Material examined. COSTA RICA • $1 \hat{\jmath}$, adult; Heredia Province, Sarapiquí County, La Virgen, Tirimbina Biological Reserve; $010^{\circ} 24^{\prime} 59^{\prime \prime} \mathrm{N}, 084^{\circ} 07^{\prime} 14^{\prime \prime} \mathrm{W} ; 149$ m alt.; 19 Jan. 2019; JK, GC leg.; UCR 23258. Specimen found in leaf litter of secondary forest.

Identification. A small, fossorial snake, maximum SVL $400 \mathrm{~mm}$, with a unique red dorsum contrasting with the brown head and a yellow nuchal collar bordered by a posterior black ring.

Remarks. A fossorial species commonly found in leaf litter, especially during rainy days at TBR. Single individuals were commonly found during VES in forested habitats and gardens.

Familia Elapidae Boie,1827

\section{Micrurus alleni (Schmidt, 1936)}

Figure $7 \mathrm{G}$

Material examined. COSTA RICA $\bullet 1 \hat{\jmath}$, adult; Heredia Province, Sarapiquí County, La Virgen, Tirimbina Biological Reserve; $010^{\circ} 24^{\prime} 25^{\prime \prime} \mathrm{N}, 084^{\circ} 07^{\prime} 12^{\prime \prime} \mathrm{W} ; 178 \mathrm{~m}$ alt.; 27 Oct. 2018; JK, GC leg.; UCR 23079. Specimen found on the ground of secondary forest.

Identification. A medium-sized coral snake, maximum SVL 700 mm (Solórzano 2004). A unique black head cap extends posteriorly forming a continuous, narrow, black stripe along the parietal suture (Köhler 2008).

Remarks. Unlike other species of the genus, it is frequently found in small streams, where it can submerge for several minutes looking for prey. It is a highly venomous species commonly observed at TBR. Single individuals were found during VES in primary and secondary forests and as occasional sightings.

Family Viperidae Oppel, 1811

\section{Porthidium nasutum (Bocourt, 1868)}

Figure $7 \mathrm{M}$

Material examined. COSTA RICA • 1 juvenile; Heredia Province, Sarapiquí County, La Virgen, Tirimbina Biological Reserve; $010^{\circ} 25^{\prime} 01^{\prime \prime} \mathrm{N}, 084^{\circ} 07^{\prime} 12^{\prime \prime} \mathrm{W} ; 164 \mathrm{~m}$ alt.; 26 Oct. 2018; JK, GC leg.; UCR 23079. Specimen found coiled on the ground of primary forest.

Identification. One of the smallest pit-vipers in the Costa Rica, maximum SVL $650 \mathrm{~mm}$, easily identified by the presence of a projection of the rostral scale resembling a proboscis (Savage 2002; Solórzano 2004).

Remarks. One of the most common venomous snakes in TBR. It is generally observed on trails, where it remains motionless displaying a sit-and-wait predatory behavior (Solórzano 2004). Single individuals were commonly found during VES in primary and secondary forests. 


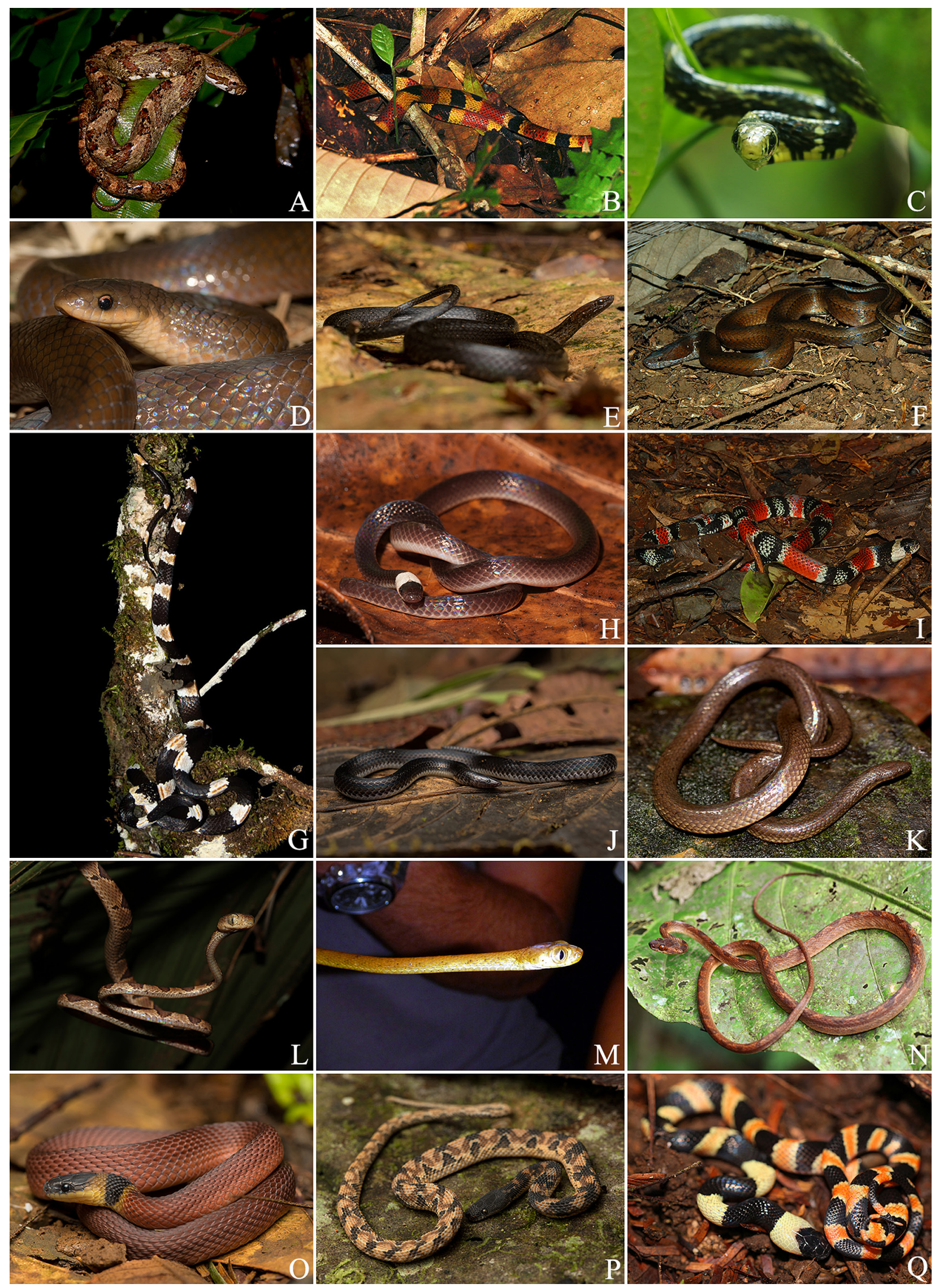

Figure 7. Species of reptiles occurring at TBR (photos by JF, JK, FT, SG and ERV, M. by C. Morgan). A. Phrynonax poecilonotus. B. Scaphiodontophis annulatus. C. Spilotes pullatus. D. Stenorrhina degenhardtii. E. Amastridium veliferum. F. Coniophanes fissidens. G. Dipsas articulata. H. Enuliophis sclateri. I. Erythrolamprus mimus. J. Geophis hoffmanni. K. Hydromorphus concolor. L. Imantodes cenchoa. M. Imantodes inornatus. N. Leptodeira septentrionalis. O. Ninia sebae. P. Nothopsis rugosus. Q. Oxyrhopus petolarius. 

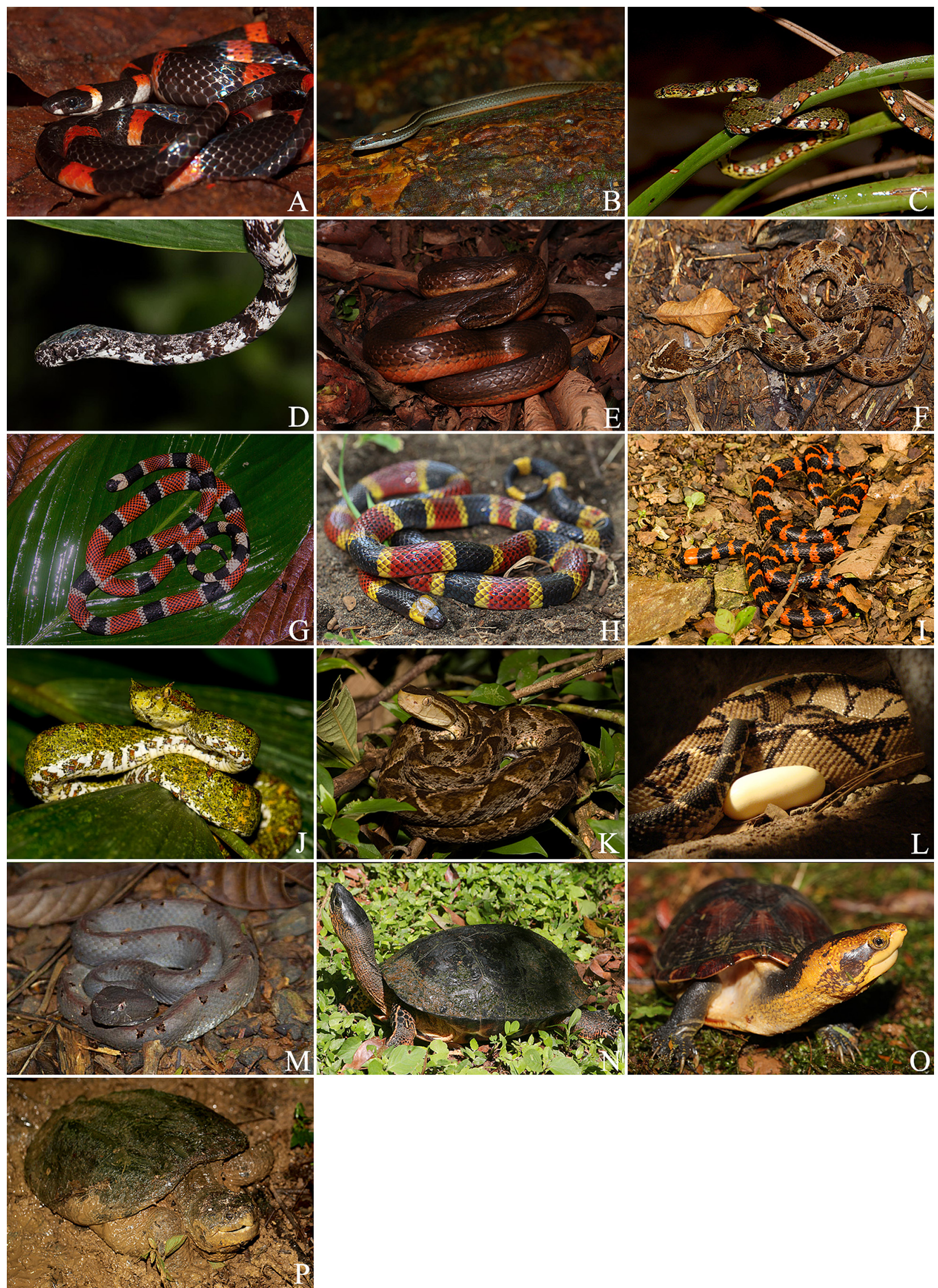

Figure 8. Species of reptiles occurring at TBR (photos by JF, JK, FT, SG and ERV, L. by G. Corrales). A. Pliocercus euryzonus. B. Rhadinaea decorata. C. Sibon longifrenis. D. Sibon nebulatus. E. Tretanorhinus nigroluteus. F. Xenodon angustirostris. G. Micrurus alleni. H. Micrurus mosquitensis. I. Micrurus multifasciatus. J. Bothriechis schlegelii. K. Bothrops asper. L. Lachesis stenophrys stenophrys (Ex-situ, Instituto Clodomiro Picado, Costa Rica). M. Porthidium nasutum. N. Rhinoclemmys funerea. O. Kinosternon leucostomum. P. Chelydra acutirostris. 
Family Chelydridae Gray, 1831

\section{Chelydra acutirostris (Peters, 1862)}

Figure 7P

Material examined. COSTA RICA • 1 adult; Heredia Province, Sarapiquí County, La Virgen, Tirimbina Biological Reserve; $010^{\circ} 25^{\prime} 01^{\prime \prime} \mathrm{N}, 084^{\circ} 07^{\prime} 12^{\prime \prime} \mathrm{W} ; 150 \mathrm{~m}$ alt.; specimen observed and photographed in the field. Species found in a pond in secondary forest.

Identification. The snapping turtle is the largest freshwater turtle in the Costa Rica, maximum SVL $494 \mathrm{~mm}$ (Köhler 2008). Its cruciform plastron, large head, and long tail distinguish the species from other freshwater turtles at TBR.

Remarks. This species displays a sit-and-wait predatory behavior, remaining still on muddy bottoms of swamps and ponds waiting for prey. It is a common species at TBR. Single individuals usually observed during VES in ponds.

\section{Discussion}

The Atlantic versant of Costa Rica presents the most diverse region for amphibians and reptiles in the country (Sasa et al. 2009). Localities such as Cahuita, Veragua and Guayacán in Limon Province and La Selva in Sarapiquí in Heredia Province, support over 90 species of herpetofauna (Guyer and Donnelly 2004; Sasa et al. 2009; Salazar-Zúñiga et al. 2019; Costa Rican Amphibian Research Center 2020; Organization for Tropical Studies 2020). Our results indicate that TBR is one of the hot spots for herpetofauna in Costa Rica, with 130 species recorded in an area of 345 ha. TBR showed a high species richness of amphibians and reptiles similar to other reserves in the Atlantic lowlands in Costa Rica (Table 4). Despite the significant sampling efforts carried out at TBR, we missed six expected species of amphibians and 12 reptiles based on the species records for the nearby (ca $5 \mathrm{~km}$ ) La Selva Biological Station (Organization for Tropical Studies 2020) (Table 4). In the wet forests of the Atlantic versant, snakes represent $65.1 \%$ of reptile diversity (Savage 2002). The same pattern is observed at TBR, where snakes represent $60.5 \%$ of the species (Savage 2002). Although snakes are abundant at

Table 4. Species of amphibians and reptiles of Atlantic lowlands natural reserves in Costa Rica: Cahuita National Park, Veragua Rainforest, Guayacan Rainforest Reserve, La Selva Research Station, and TBR (Guyer and Donnelly 2004; Sasa et al. 2009; Costa Rican Amphibian Research Center 2020; Organization for Tropical Studies 2020). Species expected for TBR shown in parentheses.

\begin{tabular}{lcccc}
\hline Reserve & Area (ha) & $\begin{array}{c}\text { Species of } \\
\text { amphibians }\end{array}$ & $\begin{array}{c}\text { Species of } \\
\text { reptiles }\end{array}$ & Total \\
\hline Cahuita & 1100 & 36 & 59 & 95 \\
Veragua & 1375 & 68 & 66 & 134 \\
Guayacan & 50 & 66 & 70 & 136 \\
La Selva & 1600 & 52 & 87 & 139 \\
TBR & 345 & $52(6)$ & $78(16)$ & 130 \\
\hline
\end{tabular}

TBR (Table 3), they are difficult to detect during surveys as they are cryptic and secretive (Green 1997). Therefore, it is remarkable that we were able to detect eight individuals of two species during a single night survey in TBR (Timmerman and Smid pers. comm.).

The most common amphibians in TBR are leaf-litter species, in the genera Craugastor, Incilius, Rhaebo, Oophaga, and Diasporus. The most abundant reptile species were those adaptable to a variety of habitatsAnolis limifrons, Bothrops asper, Basiliscus plumifrons, and Holcosus festivus - as well as forest and leaf-litter dwelling species-Corytophanes cristatus and Anolis humilis (Savage 2002). The high abundances of these species are expected, given that primary and secondary forest habitats cover most of TBR (Whitfield et al. 2007). Besides forest, a great variety of other habitats also occur in TBR: ponds, swamps, and riparian habitats along forest streams, and the Sarapiquí and Tirimbina rivers. Habitat heterogeneity is an important factor to sustain species diversity (Pineda and Halffter 2004; Tews et al. 2004; Kadmon and Allouche 2007). Although in TBR these other habitats cover a relatively small fraction of its total area, we found them important in the conservation and maintenance of herpetofauna specialized for living within them. For example, Centrolenidae are particularly abundant along forest streams (Savage 2002), while swamps and ponds provide suitable habitat for Hylidae, Phyllomedusidae, Ranidae, and Leptodactylidae. Some reptiles are also associated with specific areas; for example, Basiliscus species and Micrurus alleni are almost always found near water (Savage 2002; Solórzano 2004), as are many other species of snakes (Solórzano 2004).

Beyond being highly diverse, TBR also has a unique amphibian and reptile species assemblage. For example, the Craugastor gollmeri-species group of leaf-litter frogs has three species present in Costa Rica, and TBR is the only lowland forest locality in the country where all three species occur (Table 2). A possible explanation for this is that TBR is well connected to large natural protected areas, including Braulio Carrillo National Park, and there are reports of large mammal movement along these natural corridors into TBR (Hilje et al. unpublished data 2019). It is possible that these corridors may also provide movement opportunities for highly vagile herpetofauna species to enter TBR. Exceptionally large specimens of craugastorids and bufonids found in TBR suggest that it may lack predators for some species, thereby allowing survival of large individuals (Hilje and Sánchez 2015). Amphibians have small home ranges associated with a limited diet and microhabitat needs (Slatyer et al. 2013); TBR may be an isolated suitable habitat for species with small home ranges and highlights the importance of its preservation for the conservation of its fauna. One example is Incilius valliceps, a species of toad, which is distributed in the dry areas of Mesoamerica and known in Costa Rica only from near the Nicaragua border (Khatun et al. 2013). JK and CG recently confirmed the presence of this species within and around TBR (Klank et al. 
2020). The range extension of $I$. valliceps from relatively dry areas to wet forests in Costa Rica may be related to deforestation and global warming in the last decades (Pounds et al. 2006).

Although TBR is connected to large protected areas, it is also surrounded by pastures and plantations, and the resulting edge effect may affect abundances of certain species (Demaynadier and Hunter 1998; Cortés et al. 2008; Kurz et al. 2014). An analysis including 43 forest-dwelling amphibian species and 61 reptiles in the Neotropics found that most of them seem affected by edge effects up to $500 \mathrm{~m}$ inwards from the forest edge (Schneider-Maunoury et al. 2016). Despite TBR's relatively small size, we suggest that it has sufficient area to minimize edge effects, while permitting non-forest species to take advantage of more disturbed habitats. A reduced edge effect is important for the conservation of species that inhabit unaltered forests such as Lachesis stenophrys and Bolitoglossa alvaradoi (Savage 2002; Solórzano 2004; Leenders 2016) within the reserve. Furthermore, edge effect may also benefit non-forest species such as Rhinella horribilis and Incilius valliceps, both of which were found in abundance in open areas near the forest edges.

Decades of conservation efforts at TBR have maintained the reserve as a protected herpetofauna biodiversity hot spot in the Atlantic lowland wet tropical forests of Costa Rica. Findings from this study will support TBR's three-pillared conservation model (based on research, environmental education, and ecotourism) by providing: 1) a baseline for future herpetofauna research and conservation efforts; 2) a teaching tool for the long-running elementary school environmental education program; and 3) a means to generate further ecotourism interest in TBR as a herpetofauna biodiversity hot spot destination.

\section{Acknowledgements}

We thank the personnel, staff, managers and executive board of TBR that supported us during the different stages of this study. GC and JK thank Tirimbina Biological Reserve for the Tirimbina-UCR research grant. We thank Alejandro Solórzano who helped us to identify several snakes from photographs, and Kimberly Castro for her help in the field. JF, SG, and TP thank Juan Manuel Ley, Mariela Garcia, Jose Pablo Coto, Karen Quesada, and all the staff at TBR that have facilitated our work at the reserve. We also thank Joe Crowley, and John Urquhart for their expertise and assistance during the 2018 and 2019 surveys. We thank our interns Craig Paterson, Hannah Doddington, Henrique Pacheco, Joseph Cutler, Michelle Cooke, and Zachary Steele. Finally, we must acknowledge the contribution of all 56 course participants who provided the capacity to consistently collect data at the reserve. FT thanks Johan Smid for his friendship and companionship during 2009 surveys, and Carlos Chavarria, Bernal Rodríguez Herrera, and Melquisedec Gamba-Ríos, as well as the 2009 staff of TBR for their support during his stay at the reserve. ERV thanks the researchers who kindly provided new species records for TBR along the last 15 years. BH thanks Esmeralda Arevalo-Huezo and Mareya Villegas for their help during fieldwork. We thank G. Corrales, H. Fabian, and C. Morgan for providing photographs for some of the listed amphibian and reptile species. We thank three anonymous reviewers and the Academic Editor for comments and suggestions that greatly improved the manuscript.

\section{Authors' Contributions}

$\mathrm{BH}$ conceived the idea of this assessment, conducted transect, and leaf-litter plot surveys, collected information on all the species reported in species lists for TBR, coordinated the different tasks for the manuscript writing, analysis, and wrote the manuscript. GC and JK conducted abundance surveys and their analyses, identified species, and wrote the manuscript. JK took photographs of various specimens. JF, SG, and TP wrote the manuscript, conducted abundance surveys, and identified species. JF, SG, and TP also provided photographs for various specimens and JF prepared the mapping for this manuscript. FT conducted abundance surveys on snakes, wrote the manuscript, and provided photographs for several listed species. ERV collected amphibian and reptile species records at TBR over the last 15 years and provided photographs for several listed species.

\section{References}

Andrews RM(1979) The lizard Corytophanes cristatus: an extreme "sitand-wait" predator. Biotropica 11 (2): 136-139. https://doi.org/10. 2307/2387791

Costa Rican Amphibian Research Center (2020) https://https:// cramphibian.com. Accessed on: 2020-05-11.

Cortés AM, Ramírez-Pinilla MP, Suárez HA, Tovar E (2008) Edge effects on richness, abundance, and diversity of frogs in Andean cloud forest fragments. South American Journal of Herpetology 3(3): 213-222. https://doi.org/10.2994/1808-9798-3.3.213

Cossel JJ, Kubicki, B (2017) Field guide to the frogs and toads of Costa Rica. Kindle Direct Publishing, Seattle, 244 pp.

Crump ML, Scott NJ (1994) Visual encounter surveys. In: Heyer W, Donnelly M, McDiarmid R, Hayek L, Foster M (Eds) Measuring and monitoring biological diversity: standard methods for amphibians. Smithsonian Institution Press, Washington, DC/London, 84-92.

Demaynadier PG, Hunter ML (1998) Effects of silvicultural edges on the distribution and abundance of amphibians in Maine. Conservation Biology 12 (2): 340-352. https://doi.org/10.1111/j.1523-1739. 1998.96412.x

Gentry A (1992) Tropical forest biodiversity: distributional patterns and their conservational Significance. Oikos 63 (1): 19-28.

Green H (1997) Snakes: the evolution of mystery in nature. University of California Press, Berkeley, 366 pp.

Guyer C, Donnelly MA (2004) Amphibians and reptiles of La Selva, Costa Rica, and the Caribbean Slope: a comprehensive guide. University of California Press, Berkley, 367 pp.

Hilje B, Aide TM (2012a) Recovery of amphibian species richness and composition in a chronosequence of secondary forests, northeastern Costa Rica. Biological Conservation 146 (1): 170-176.

Hilje B, Aide TM (2012b) Calling activity of the Common Tink Frog (Diasporus diastema) (Eleutherodactylidae) in secondary forests 
of the Caribbean of Costa Rica. Tropical Conservation Science 5 (1): 25-37.

Hilje B, Sanchez NV (2015) Incilius melanochlorus and Craugastor mimus. Body gigantism. Mesoamerican Herpetology 2 (3): 330332.

IUCN (2020) International Union for the Conservation of Nature. https://www.iucnredlist.org. Accessed on: 2020-05-11.

Kadmon R, Allouche O (2007) Integrating the effects of area, isolation, and habitat heterogeneity on species diversity: a unification of island biogeography and niche theory. The American Naturalist 170 (3): 443-454. https://doi.org/10.1086/519853

Khatun K, Imbach P, Zamora JC (2013) An assessment of climate change impacts on the tropical forests of Central America using the Holdridge Life Zone (HLZ) land classification system. iForest 6 (4): 183-189. https://doi.org/10.3832/ifor0743-006

Klank J, Chaves G, Arias E (2020) Range expansion of the Gulf Coast Toad, Incilius valliceps (Wiegmann, 1833) (Anura, Bufonidae), from Costa Rica. Check List 16 (3): 753-757. https://doi.org/10. $15560 / 16.3 .753$

Kindt R, Coe R (2005) Tree diversity analysis: a manual and software for common statistical methods for ecological and biodiversity studies. World Agroforestry Centre, Nairobi, 153 pp.

Köhler G (2008) Reptiles of Central America. Herpeton Verlag, Offenbach, $400 \mathrm{pp}$.

Kurz DJ, Nowakowski AJ, Tingley MW, Donnelly MA, Wilcove DS (2014) Forest-land use complementarity modifies community structure of a tropical herpetofauna. Biological Conservation 170: 246-255. https://doi.org/10.1016/j.biocon.2013.12.027

Leenders T (2016) Amphibians of Costa Rica. Cornell University Press, Ithaca/London, $544 \mathrm{pp}$.

Leenders T (2019) Reptiles of Costa Rica. Cornell University Press, Ithaca/London, $531 \mathrm{pp}$.

Organization for Tropical Studies (2020) https://tropicalstudies.org. Accessed on: 2020-05-11.

Pineda E, Halffter G (2004) Species diversity and habitat fragmentation: frogs in a tropical montane landscape in Mexico. Biological Conservation 117 (5): 499-508. https://doi.org/10.1016/j. biocon.2003.08.009

Pounds JA, Bustamante MR, Coloma LA, Consuegra JA, Fogden MPL, Foster PN, La Marca E, Masters KL, Merino-Viteri A, Puschendorf R, Ron SR, Sánchez-Azofeifa GA, Still CJ, Young BE (2006) Widespread amphibian extinctions from epidemic disease driven by global warming. Nature 439: 161-167. https://doi.org/ 10.1038 /nature04246

Racine JS (2012) RStudio: a platform-independent IDE for R and Sweave. Journal of Applied Econometrics 27 (1): 167-172. https:// doi.org/10.1002/jae.1278

Rand AS, Drewry GE (1994) Acoustic monitoring at fixed sites. In:
Heyer W, Donnelly M, McDiarmid R, Hayek L, Foster M (Eds) Measuring and monitoring biological diversity: standard methods for amphibians. Smithsonian Institution Press, Washington, DC/ London, 150-153.

Reserva Tirimbina (2020) http://reservatirimbina.org. Accessed on : 2020-05-11.

Salazar-Zúñiga JA, Chaves-Acuña W, Chaves G, Acuña A, AbarcaOdio JI, Lobon-Rovira J, Gómez-Méndez E, Gutiérrez-Vannucchi AC, Bolaños F (2019) The most frog-diverse place in Middle America, with notes on the conservation status of eight threatened species of amphibians. Amphibian and Reptile Conservation 13 (2): 304-322.

Sasa M, Chaves G, Porras LW (2009) Conservation and diversity of the Costa Rican herpetofauna: status and future perspectives. In: Wilson LD, Townsend JH, Johnson JD (Eds) Conservation of Mesoamerican amphibians and reptiles. Eagle Mountain Publishing, Eagle Mountain, Utah, 510-603.

Savage JM (2002) The amphibians and reptiles of Costa Rica: a herpetofauna between two continents, between two seas. University of Chicago Press, Chicago, 934 pp.

Schneider-Maunoury L, Lefebvre V, Ewers RM, Medina-Rangel GF, Peres CA, Somarriba E, Urbina-Cardona N, Pfeifer M (2016) Abundance signals of amphibians and reptiles indicate strong edge effects in Neotropical fragmented forest landscapes. Biological Conservation 200: 207-215. https://doi.org/10.1016/j.biocon. 2016.06.011

Scott NJ, Woodward BD (1994) Surveys at breeding sites. In: Heyer W, Donnelly M, McDiarmid R, Hayek L, Foster M (Eds) Measuring and monitoring biological diversity: standard methods for amphibians. Smithsonian Institution Press, Washington, DC/London, 118-125.

Slatyer RA, Hirst M, Sexton JP (2013) Niche breadth predicts geographical range size: a general ecological pattern. Ecology Letters 16 (8): 1104-1114.

Solórzano A (2014) Gymnopis multiplicata. Size. Mesoamerican Herpetology 1 (2): 281-282.

Solórzano A (2004) Serpientes de Costa Rica. Editorial INBio, Heredia, $791 \mathrm{pp}$.

Tews J, Brose U, Grimm V, Tielbörger K, Wichmann MC, Schwager M, Jeltsch F (2004) Animal species diversity driven by habitat heterogeneity/diversity: the importance of keystone structures. Journal of Biogeography 31 (1): 79-92. https://doi.org/10.1046/j.03050270.2003.00994.x

Whitfield SM., Bell KE, Philippi T, Sasa M, Bolaños F, Chaves G, Savage JM, Donnelly M.A (2007) Amphibian and reptile declines over 35 years at La Selva, Costa Rica. Proceedings of the National Academy of Sciences 104 (20): 8352-8356. https://doi. org/10.1073/pnas.0611256104 